Western\&Graduate\&PostdoctoralStudies

Western University

Scholarship@Western

Electronic Thesis and Dissertation Repository

9-11-2013 12:00 AM

\title{
Aging and Stabilization of Pyrolitic Bio-Oils and Model Compounds
}

A. G. Manjula Taranganie Siriwardhana, The University of Western Ontario

Supervisor: Franco Berruti, The University of Western Ontario

Joint Supervisor: Cedric Briens, The University of Western Ontario

A thesis submitted in partial fulfillment of the requirements for the Master of Engineering Science degree in Chemical and Biochemical Engineering

(c) A. G. Manjula Taranganie Siriwardhana 2013

Follow this and additional works at: https://ir.lib.uwo.ca/etd

Part of the Bioresource and Agricultural Engineering Commons, Other Chemical Engineering Commons, and the Power and Energy Commons

\section{Recommended Citation}

Siriwardhana, A. G. Manjula Taranganie, "Aging and Stabilization of Pyrolitic Bio-Oils and Model Compounds" (2013). Electronic Thesis and Dissertation Repository. 1719.

https://ir.lib.uwo.ca/etd/1719

This Dissertation/Thesis is brought to you for free and open access by Scholarship@Western. It has been accepted for inclusion in Electronic Thesis and Dissertation Repository by an authorized administrator of Scholarship@Western. For more information, please contact wlswadmin@uwo.ca. 


\section{AGING AND STABILIZATION OF PYROLITIC BIO-OILS AND MODEL COMPOUNDS}

Thesis format: Integrated Article

by

A. G. Manjula Taranganie Siriwardhana

Graduate Program in Chemical and Biochemical Engineering

A thesis submitted in partial fulfillment

of the requirements for the degree of

Master of Engineering Science (MESc)

The School of Graduate and Postdoctoral Studies

The University of Western Ontario

London, Ontario, Canada

(C) Manjula Siriwardhana 2013 


\begin{abstract}
When compared to conventional liquid fuels, bio-oil has several undesired properties such as high viscosity, high acidity, high molecular weight, instability, and phase separation upon aging. Therefore, bio-oil needs further stabilization and upgrading before it can be used as a fuel in engines. Phase separation is considered as one of the major issues because it is detrimental to any fuel application and creates problems in storage, transportation and upgrading of bio-oils. This thesis investigates the phase separation of hardwood derived bio-oil under accelerated aging conditions. Different alcohols are used as stabilizing agents and the minimum required amount of alcohol for preventing phase separation for a given period of time is determined. The evolution in chemical composition of bio-oil during aging is studied using model compounds. Finally, this thesis explores the use of fractional condensation during bio-oil production to obtain a more stable bio-oil.
\end{abstract}

Keywords: Bio-oil characterization, bio-oil stability, aging of bio-oil, phase separation of bio-oil, model compounds, fractional condensation. 


\section{Co-authorship statement}

\section{Chapter 1}

\section{Article title:}

Quantification of phase separation of hardwood derived bio-oil and changes of physical and chemical compositions before and after phase separation.

\section{Authors:}

Manjula Siriwardhana, Franco Berruti, Cedric Briens

\section{Article status:}

Yet to be submitted for publications

Contributions:

Manjula Siriwardhana performed all experimental work, data analysis, method development and writing. Cedric Briens and Franco Berruti provided guidance, supervision and revised drafts of the work.

\section{Chapter 2}

\section{Article title:}

Understanding the chemical reactions that occur during bio-oil aging: a model compound study

Authors:

Manjula Siriwardhana, Cedric Briens, Franco Berruti

Article status:

Yet to be submitted for publications

Contributions:

Manjula Siriwardhana performed all experimental work, data analysis, method development and writing. Cedric Briens and Franco Berruti provided guidance, supervision and revised drafts of the work.

\section{Chapter 3}

\section{Article title:}

Change in physical properties and chemical composition during aging of dry birch bark bio-oil from fractional condensation

\section{Authors:}

Manjula Siriwardhana, Franco Berruti, Cedric Briens

Article status:

Yet to be submitted for publications

Contributions:

Manjula Siriwardhana performed all experimental work, data analysis, method development and writing. Cedric Briens and Franco Berruti provided guidance, supervision and revised drafts of the work. 


\section{Acknowledgements}

The author wishes to express her deepest gratitude and sincere appreciations to her supervisors, Prof. F. Berruti and Prof. C. Briens, first, for giving her this truly excited and valuable opportunity to explore a new world and secondly, for their excellent advices and invaluable guidance throughout her research stay at ICFAR.

Thanks are also extended to the National Science and Engineering Research Council of Canada (NSERC) for providing financial assistance for her stay at ICFAR.

Sincere thanks and appreciations are expressed to Dr. Guus van Rossum for his support and advices during the initial stages of her research. The author would like to thank $\mathrm{C}$. Xu and Dr. Z. Yuan for their support in her research by providing materials and assistance whenever requested. Dr. A. Ray's advices and encouragements are also greatly remembered here. Caitlin Marshall's consistent support in data analysis and other assistance during analytical lab work is greatly appreciated too. Thank you to the administration staff at ICFAR and CBE, UWO.

Priceless thanks, love, utmost respect and deep sense of gratitude are expressed to her parents, Nangi and Bhanu and sisters, to whom if not for their unconditional love, care and patience the author would not have come along this journey.

Finally, author wishes to dedicate this thesis for her parents, Nangi and Bhanu. Thanks for being with me in all endeavors in life, happiness and sorrow. 


\section{Table of Contents}

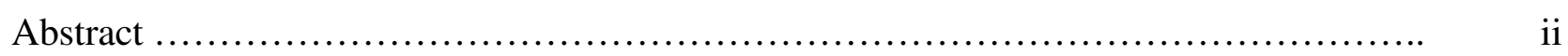

Co-authorship statement.............................................................................................

Acknowledgments ............................................................ iv

Table of Contents ............................................................. $\mathrm{v}$

List of Tables ...................................................................... viii

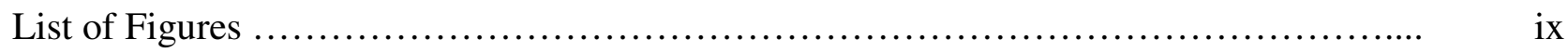

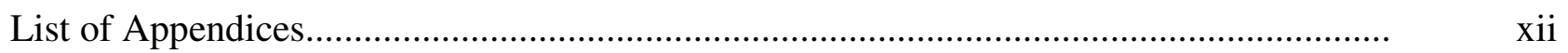

Introduction ............................................................................ xii

Chapter 1 ......................................................................... 1

1. Quantification of phase separation of hardwood derived bio-oil and changes of physical and chemical compositions before and after phase separation.................. 1

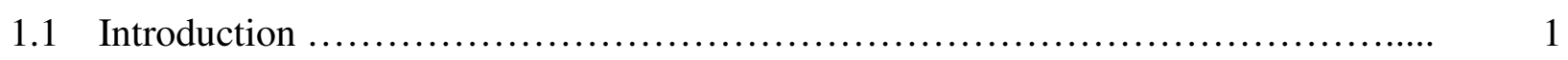

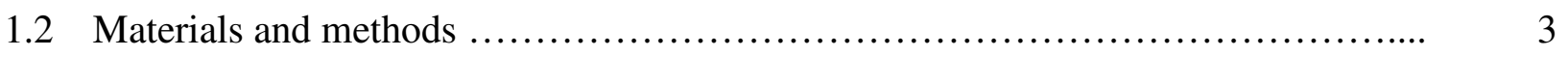

1.2.1 Chemicals and materials ............................................... 3

1.2.2 Quantification of phase separation due to aging of bio-oil ..................... 3

1.2.3 Chemical composition of top and bottom phases with aging time ............... 4

1.2.4 Prevention of phase separation of bio-oil by adding solvents ................... 4

1.2.5 Chemical composition of bio-oil during aging with isopropanol as a solvent ..... 5

1.2.6 Quantification of phase separation by water titration ......................... 5

1.2.7 Higher heating value .................................................. 5

1.3 Results and discussion ................................................... 5 
1.3.1 Is phase separation effective? ............................................ 5

1.3.2 What triggers phase separation? ..................................... 6

1.3.3 What happens after the phase separation occurs?............................. 7

1.3.4 What happens when solvents are added to bio-oil?........................... 9

1.3.5 What happens when water is added to bio-oil?.............................. 13

$\begin{array}{ll}\text { 1.3.6 Change of the higher heating value (HHV) of bio-oil with isopropanol as a } & 14\end{array}$ solvent

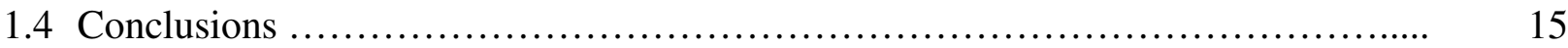

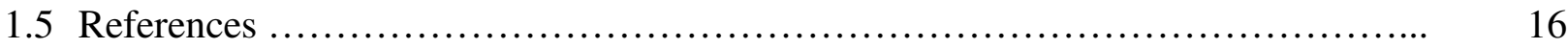

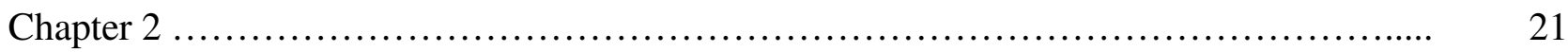

2. Understanding the chemical reaction happens during bio-oil aging: A model 21 compound study

2.1 Introduction

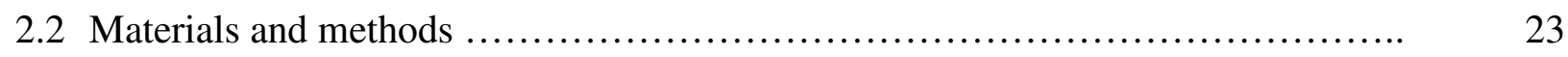

2.2.1 Chemicals and materials ............................................ 23

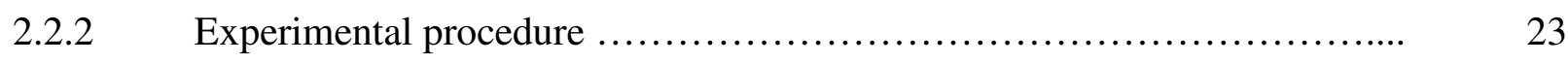

2.2.3 Chemical composition of samples with aging time .......................... 24

2.3 Results and discussion ..................................................... 25

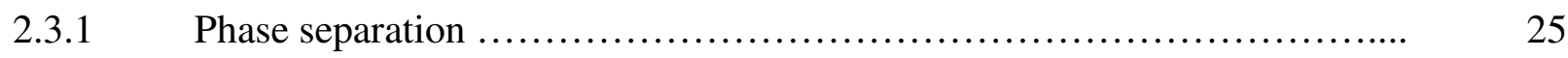

2.3.2 Conversion of acetic acid ......................................... 29

2.3.3 Conversion of ketones and aldehydes ................................... 29

2.3.4 Conversion of Phenols .................................................. 33

2.3.5 What happened to furans? .......................................... 34

2.3.6 Is there an impact from operating conditions of the GC-MS towards results? 34

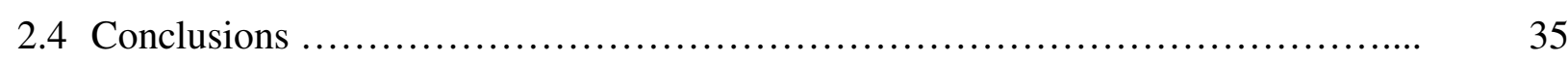

2.5 References .................................................................... 36 


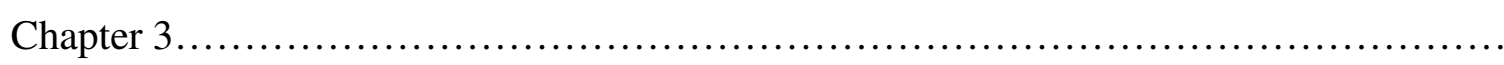

3. Change in physical properties and chemical composition during aging of dry birch bark bio-oil from fractional condensation

3.1 Introduction

3.2 Materials and methods

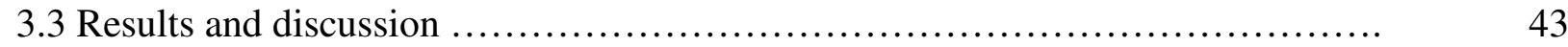

3.3.1 Properties of different fractions of bio-oil derived from birch bark ............ 43

3.3.2 Effect of the temperature of second condenser............................ 44

3.3.3 GC-MS analysis for aqueous and second condenser fractions ................. 45

3.3.4 Aging of different fractions of birch bark bio-oil ......................... 46

3.3.5 Change in higher heating value of second condenser cut .................... 49

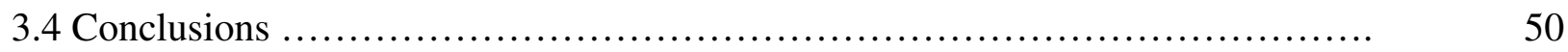

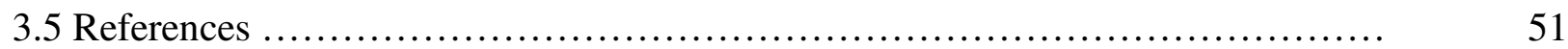

4. Conclusions and recommendations...................................... 55

4.1 Conclusions.......................................................... 55

4.2 Recommendations................................................... 56 


\section{List of Tables}

Table 2.1: $\quad$ Model compounds and their concentrations in the base mixture......... 23

Table 2.2: $\quad$ Special conditions of the runs. ............................... 24

Table 2.3: $\quad$ Time required for phase separation. ........................... 25

Table 2.4: Water content of each phase after 10 days of aging at $80{ }^{\circ} \mathrm{C} . \ldots \ldots \ldots . . .26$ 


\section{List of Figures}

Figure 1.1: The composition of top and bottom phases after phase separation occurs (at 24 hours) (a) top phase (b) bottom phase.................... 6

Figure 1.2: $\quad$ Change in chemical composition of BTG bio-oil during aging at $80{ }^{\circ} \mathrm{C}$.

Figure 1.3: Chemical composition of bio-oil before phase separation and combined valued for top and bottom phases after phase separation.

Figure 1.4: Water content of (a) top and bottom phases of aged, centrifuged and settled bio-oil, and (b) the system (by water balance).

Figure 1.5: Time taken for phase separation to occur at different percentage of stabilizers, under accelerating aging conditions (at $80{ }^{\circ} \mathrm{C}$ ).

Figure 1.6: $\quad$ Change in chemical composition of BTG bio-oil with $10 \%$ isopropanol during aging at $80{ }^{\circ} \mathrm{C}$.

Figure 1.7: The difference of chemical composition of BTG bio-oil with $20 \%$ isopropanol and $10 \%$ isopropanol during aging at $80^{\circ} \mathrm{C}$.

Figure 1.8: The variation of water content in the top and bottom phases of bio-oil Vs. water content in the system.

Figure 1.9: $\quad$ Change in HHV of bio-oil with $10 \%$ and $20 \%$ isopropanol and combined top and bottom phases without solvent (values are combined based on their weight $\%$ at respective time of aging).

Figure 2.1: $\quad$ Conversion of acetic acid along the aging period of model compound with and without alcohol.

Figure 2.2: $\quad$ Evolution of esters along the aging period of model compound with alcohol, (a) Acetic acid, 1-methylethyl ester, (b) Ethyl acetate. 
Figure 2.3: $\quad$ Evolution of 1-hydroxy-2-propanone along the aging period of model compound with and without alcohol.

Figure 2.4: $\quad$ Evolution of cyclopentanone along the aging period of model compound with and without alcohol.

Figure 2.5: $\quad$ Evolution of 1,1-dimethoxycyclopentane along the aging period of model compound with and without alcohol.

Figure 2.6: $\quad$ Evolution of 2,2-dimethoxy- propane along the aging period of model compound with and without alcohol.

Figure 2.7: Evolution of phenolics along the aging period of model compound with and without alcohol; (a) phenol, (b) phenol, 2-methoxy-, (c) vanillin ...

Figure 3.1: $\quad$ The schematic diagram of the fluidized bed reactor and the condenser train

Figure 3.2: $\quad$ Water content, $\mathrm{pH}$ and HHV of different fractions of bio-oil derived from birch bark (with the condenser 2 maintained at $70{ }^{\circ} \mathrm{C}$ )

Figure 3.3: The properties of second condenser cut of bio-oil at different temperatures of condensation

Figure 3.4: $\quad$ The GS-MS spectra for second condenser cut and aqueous cut.

Figure 3.5: Change in chemical composition of second condenser cut over the aging period.

Figure 3.6: Change in chemical composition of the mixture of second condenser cut and aqueous cut (condenser 3 ) over the aging period.

Figure 3.7: Change in chemical composition of combination of second condenser cut and solid cut (condenser 1) over the aging period. 
Figure 3.8: $\quad$ Change in higher heating value of second condenser cut over the aging period. . 


\section{List of Appendices}

Appendix A: Example of manual integration of GC-MS/FID data for the points of time $=3 \mathrm{hrs}$

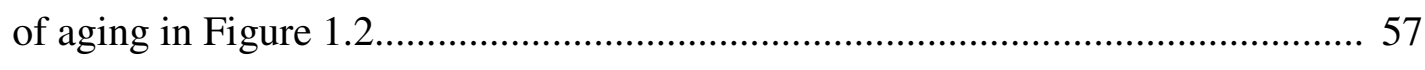

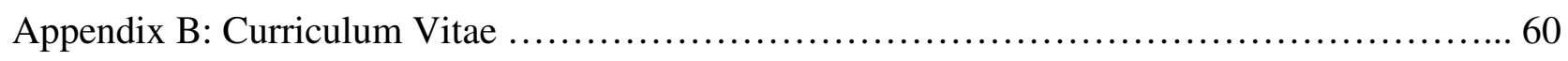




\section{Introduction}

Conversion of biomass into bio-oil is one of the most promising methods to replace depleting fossil fuel resources with renewable feedstocks. Pyrolysis is a thermochemical process that converts solid biomass into a liquid fuel, which is called bio-oil [1]. At room temperature, bio-oil is usually, initially, a single phase, dark, viscous liquid that contains more than 300 chemical components [1-4].

However, when compared to conventional liquid fuels, bio-oil has several undesired properties such as high viscosity, high acidity, high molecular weight, instability and phase separation upon aging, and its properties, such as viscosity, change with storage time and temperature [1- 4]. Further, the high oxygen (typically 45-50 wt\%) and water contents (typically 15-30 wt\%) of pyrolysis oil result in a lower energy density than conventional fuel oils [5,6]. Amongst all the above deleterious properties, instability is one of the biggest challenges because it not only changes bio-oil properties such as viscosity, but also induces phase separation that prevents the application of bio-oil as a fuel. Therefore, bio-oil needs further stabilization and upgrading before it can be used as a fuel in existing engines [1].

The main objective of this thesis, therefore, is the development of practical solutions to eliminate or reduce bio-oil aging. A first step is to characterize aging. In most of the past literature studies, the stability of pyrolysis liquids has been measured as an absolute increase in its viscosity during typical storage or during an accelerated aging test [2- 4]. In addition to increased viscosity, storage (especially at elevated temperatures) has resulted in increasing water content [7], increasing molecular weight [1-4,8] and phase separation [1]. Several studies show that the weight-average molecular weight of aged bio-oil correlates linearly with its viscosity [4, 9]. This is mainly due to the polymerization reactions between bio-oil components during storage [4, 9]. Further, Oasmaa et al. [10] showed that the change in viscosity is well correlated to the change in carbonyl content of the bio-oil. However, increases in $\mathrm{pH}$ or Total Acid Number (TAN) are barely noticeable during aging [3,9] and hence, they are not good indicators for the measurement of the stability or degree of aging of bio-oil [11].

To measure the degree of instability during aging, a method has been introduced to accelerate aging by increasing the storage temperature [4]. Czernik et al. [3] concluded from aging data, 
that the aging reactions are relatively similar over the $37-90{ }^{\circ} \mathrm{C}$ temperature range [4] and therefore, chemical changes during accelerated aging are representative of the changes that occur during normal aging. For example, Czernik et al. [4] demonstrated that equivalent viscosities are obtained in oak pyrolysis oil after 3 months of aging at room temperature, 4 days of aging at 60 ${ }^{\circ} \mathrm{C}$ or 6 hours of aging at $90{ }^{\circ} \mathrm{C}$. In the same way, Chaala et al. [12] reported that the increase in molecular weight observed after heating softwood bark pyrolysis oil for 1 week at $80{ }^{\circ} \mathrm{C}$ is equivalent to keeping the sample for 1 year at room temperature.

As a result of ongoing chemical reactions, polymerization processes, and initial high water concentrations, during aging, bio-oil spontaneously separates into two phases, i.e., a more polar aqueous phase, which consist mainly of water soluble compounds, and a non-polar viscous bottom phase, which consists of lignin extractives [2, 13-14]. The quantity of each phase depends on many parameters such as the type and properties of the feedstock (e.g. water content), the process parameters (e.g. temperature) and the storage conditions and period. From all the above physical properties that have been considered to characterize bio-oil stability, except phase separation, the desired range depends on the type of application of the fuel. Therefore, phase separation is considered as one of the major issues because it is detrimental to any fuel application and it creates problems in storage, transportation and upgrading of bio-oils.

Therefore, the first specific objective of this thesis, addressed in Chapter 1, is to analyze the phase separation behaviour of fast pyrolysis bio-oil from hardwood. Its second specific objective is to identify solvents and additives that are effective at retarding phase separation.

Additives, especially, low viscosity alcohols, can reduce both the initial viscosity of bio-oil and mitigate its increase during aging [2, 3, 15, 16]. Ethyl Acetate, acetone, methanol, ethanol and isopropanol are the additives that were the most commonly used in previous studies [1-4, 15]. Diebold and Czernik [2] showed that the effect of the solvents on viscosity reduction was greater than would be expected from physical dilution. The authors also found that the addition of methanol shortly after producing a hardwood bio-oil was significantly more effective than after aging at $90{ }^{\circ} \mathrm{C}$ for 20.5 hours. This suggests that beneficial chemical reactions occur between bio-oil and solvent [1]. 
Boucher et al. [16] have shown that adding methanol is useful for delaying the phase separation of vacuum pyrolysis softwood bark bio-oil. However, most of the recent upgrading studies use a high concentration of solvent, reaching more than $50 \mathrm{wt} \%$ of the mixture $[17,18]$.

Therefore, a third specific objective of the thesis is to investigate the changes in chemical composition of bio-oil before and after the phase separation, and when adding additives. This is also addressed in Chapter 1. To better understand the fundamental aspects of such changes and develop the best mitigation strategies, the aging behaviour of individual bio-oil model compounds are investigated in Chapter 2.

As it was discussed before, bio-oil is a poorly defined mixture of acids, alcohols, aldehydes, esters, ketones, sugars, phenols, guaiacols, syringols, furans, and multifunctional compounds. The literature indicates that the whole picture of fuel stability is very complex and that there is likely no single explanation for all the phenomena associated with bio-oil degradation. It has been observed that, during aging, different unsaturated and reactive components interact by means of polymerization, esterification, acetalization, oxidization or dimerization to form larger molecules and consequently cause changes in physical properties, such as viscosity [1- 4]. Diebold [1] identified the following reactions as the main apparent interactions during bio-oil aging:

- Organic acids + alcohols $\rightarrow$ esters + water.

- Organic acids + olefins $\rightarrow$ esters.

- $\quad$ Aldehydes + water $\rightarrow$ hydrates.

- Aldehydes + alcohols $\rightarrow$ hemiacetals + acetals + water.

- Aldehydes $\rightarrow$ oligomers + resins.

- Aldehydes + phenolics $\rightarrow$ resins + water.

- Unsaturated compounds $\rightarrow$ polyolefins.

Understanding how and why polymerization and other reactions occur is important to develop methods to stabilize or upgrade bio-oil. Significant efforts have been made to understand the polymerization and other chemical reactions between solvents (mainly low molecular mass alcohols) and bio-oil [17 - 20]. Due to the extreme complexity of bio-oils, the contribution of the main components to the polymerization reactions is not yet fully understood. Therefore, several 
studies have used model compound mixtures on polymerization and other ongoing chemical reactions in bio-oil [21 - 26]. Gunawan et al. [27] and Hu et al. [21], for example, have used biooil model compounds to understand the chemical reactions that are happening at elevated temperatures $\left(70-170{ }^{\circ} \mathrm{C}\right)$, but did not investigate what is happening when bio-oil is heated or stored for a prolonged time. All these model compound studies have been executed to understand the chemical reactions that are occurring within 2 hours of heating time.

The quality and stability indicators of bio-oil are directly related to the chemical composition of these oils [28]. Therefore, the quality or the stability of bio-oil can be improved by changing the chemical composition of the bio-oil produced. This has been achieved by upgrading biomass using torrefaction processes [29, 30] or other pretreatment processes [31], by controlling the pyrolysis conditions [32 - 36], by using only a selective part of feedstock biomass with specific qualities such as cellulose, hemicellulose or lignin [32 -33], by downstream fractionating of biooil by methods such as molecular distillation [37] or by changing the temperature of the condenser [38]. Oasmaa [39] has found that the concentration method, which removes part of the water and light volatiles and replaces them with alcohols can improve the quality (viscosity, flash point and stability) of the bio-oil. However, removing water is always accompanied by the loss of organic vapors in the condenser and hence a reduction in bio-oil yield [34]. Demirbas [33] and Dong et al. [32] studied the influence of pyrolysis temperature on the compounds and composition of bio-oil obtained from fast pyrolysis [33].

It is well known that the temperature of the condenser affect the bio-oil yield and composition [40]. In the recent years, lot of efforts has been made for the usage of a series of condensers to collect bio-oil with specific fuel properties [37 - 38, 41 - 42]. Westerhof et al. [38], Pollard et al. [41], Tzanetakis et al. [42] and Chen et al. [43] studied the effect of selective condensation on bio-oil characteristics. These authors concluded that the liquid fraction collected from condensing each stage has unique physical and chemical properties, and that the stage fractionation can be used to control the water and acid contents of the bio-oil product. Based on these results, Westerhof et al. [38] concluded that the fractional condensation is a promising cheap downstream approach to concentrate compounds and thus, to control the quality of biooils, making it more suitable for further upgrading and/or direct application. In the same way, Guo stated that the separation of the light fraction, which has high contents of water and acids, 
has the dual advantage of increasing the combustibility and decreasing the corrosiveness of the other oil fractions [44]. Tzanetakis et al. [42] found that they could use fractional condensation to produce a homogeneous single phase liquid bio-oil that remained a single phase after 7 months of storage at room temperature. Tumbalam Gooty [45] also experienced a similar result from fractional condensation.

Therefore, the fourth specific objective of this thesis is to investigate the use of fractional condensation of pyrolysis vapors to obtain bio-oils that are more resistant to aging. The thesis is formatted according to the "integrated article format" which includes 3 articles in Chapters 1, 2 and 3 .

To summarize, this thesis focuses on the development of practical solutions to eliminate or reduce bio-oil aging. It proceeds through several steps:

1) Development of a reliable and relevant method to characterize aging. It focuses on the separation behaviour of fast pyrolysis bio-oil, which is a serious problem for any practical application of bio-oil (Chapter 1).

2) Identification of solvents and additives that are effective at retarding phase separation (Chapter 1).

3) Investigate the changes in chemical composition of bio-oil before and after the phase separation, and when adding additives (Chapter 1). To better understand these changes and develop the best mitigation strategies, changes obtained with model compounds of bio-oil are also studied (Chapter 2).

4) Determine whether fractional condensation of pyrolysis vapors can be used to obtain biooils that are more resistant to aging (Chapter 3). 


\section{References}

[1] Diebold, J. P. (2000). A review of the chemical and physical mechanisms of the storage stability of fast pyrolysis bio-oils. NREL/SR-570-27613. Colorado, National Renewable Energy Laboratory.

[2] Diebold, J. P. and Czernik, S. (1997). Additives to lower and stabilize the viscosity of pyrolysis oil during storage, Energy \& Fuels 1997, 11, 1081-1091

[3] Oasmaa, A. and Kuoppala, E. (2003). Fast pyrolysis of forestry residue. 3. Storage stability of liquid fuel. Energy \& Fuels 2003, 17, 1075-1084

[4] Czernik, S., Johnson, D. K., Black, S. (1994). Stability of wood fast pyrolysis oil. Biomass and Bioenergy, 7(1-6), 187- 192.

[5] Oasmaa, A. and Czernik, S. (1999). Fuel oil quality of biomass pyrolysis oils- state of the art for the end users. Energy \& Fuels 1999, 13, 914-921.

[6] Demirbas, A. (2007). The influence of temperature on the yield of compounds existing in bio-oils obtained from biomass samples via pyrolysis. Fuel Processing Technology, 88(2007), 591-597.

[7] Batts, B.D. and Fathoni, A.Z. (1991). A literature review on fuel stability with particular emphasis on diesel oil. Energy \& Fuels 1991, 5, 2-21.

[8] Vispute, T. (2011). Pyrolysis oils: Characterization, stability analysis and catalytic upgrading to fuels and chemicals. Open access dissertation, paper 349, Amherst, University of Massachusetts. http://scholarworks.umass.edu/open_access_dissertations/349

[9] Kim, T. S., Kim, J. Y., Kim, K. H., Lee, S. and Choi, D. (2012). The effect of storage duration on bio-oil properties. Journal of Analytical and Applied Pyrolysis, 95(2012), 118-125. 
[10] Oasmaa, A., Korhonen, J. and Kuoppala, E. (2011). An approach for stability measurement of wood-based fast pyrolysis bio-oil. Energy \& Fuels 2011, 25, 3307-3313.

[11] Oasmaa, A., Elliott, D. C. and Korhonen, J. (2010). Acidity of biomass fast pyrolysis biooil. Energy \& Fuels 2010, 24, 6548-6554.

[12] Chaala, A., Ba, T., Garcia-Perez, M. and Roy, C. (2004). Colloidal properties of bio-oils obtained by vacuum pyrolysis of softwood bark: Aging and thermal stability. Energy \& Fuels 2004, 18, 1535-1542.

[13] Chen, H. W., Song, Q. H., Liao, B. and Guo, Q. X. (2011). Further separation, characterization and upgrading for upper and bottom layer from phase separation of biomass pyrolysis oils. Energy \& Fuels 2011, 25, 4655-4661.

[14] Ba, T., Chaala, A., Garcia-Perez, M., Rodrigue, D. and Roy, C. (2004). Colloidal properties of bio-oils obtained by vacuum pyrolysis of softwood bark. Characterization of water-soluble and water-insoluble fractions. Energy \& Fuels 2004,18, 704-712.

[15] Qiang, L., Xu-lai, Y. and Xi-feng, Z. (2008). Analysis on chemical and physical properties of bio-oil pyrolysis from rice husk. Journal of Analytical and Applied Pyrolysis. 82(2008), 191-198.

[16] Boucher, M. E., Chaala, A., Pakdel, H. and Roy, C. (2000). Bio-oils obtained by vacuum pyrolysis of softwood bark as a liquid fuel for gas turbine. Part II: Stability and aging of bio-oil and its blends with methanol and a pyrolytic aqueous phase. Biomass and Bioenergy, 19(2000), 351-361.

[17] Li., X., Gunawan, R., Lievens, C., Wang, Y., Mourant, D., Wang, S., Wu, H., GarciaPerez, M. and Li, C. Z. (2011).Simultaneous catalytic esterification of carboxylic acids and acetalisation of aldehydes in fast pyrolysis bio-oil from mallee biomass. Fuel, 90(2011), 2530-2537.

[18] Hu, X., Gunawan, R., Mourant, D., Lievens, C., Li, X., Zhang, S. and Chaiwat, W. (2012). Acid-catalysed reaction between methanol and bio-oil from fast pyrolysis of mallee bark. Fuel, 97(2012), 512-522. 
[19] Hu, X., Mourant, D., Wang, Y., Wu, L., Chaiwat, W. Gunawan, R., Gholizadeh, M., Lievens, C., Garcia-Perez, M., Li, C. Z. (2013). Acid-catalysed treatment of the mallee leaf bio-oil with methanol: Effects of molecular structure of carboxylic acids and esters on their conversion. Fuel Processing Technology, 106(2013), 569-576.

[20] Moens, L., Black, S. K., Myers, M. D. and Czernik, S. (2009). Study of the neutralization and stabilization of a mixed hardwood bio-oil. Energy \& Fuels 2009, 23, 2695-2699.

[21] Hu, X., Wang, Y., Mourant, D., Gunawan, R., Lievens, C., Chaiwat, W., Gholizadeh, M., Wu, L., Li, X. and Li, C. Z. (2012). Polymerization on heating up of bio-oil: A model compound study. AIChE Journal, 00(0), 1-10. DOI: 10.1002/aic.13857.

[22] Wang, S., Guo, Z., Cai, Q. and Guo, L. (2012). Catalytic conversion of carboxylic acids in bio-oil for liquid hydrocarbons production. Biomass and Bioenergy, 45 (2012), 138143.

[23] Lohitharn, N., and Shanks, B. H. (2009). Upgrading of bio-oil: Effect of light aldehydes on acetic acid removal via esterification. Catalysis Communications, 11 (2009), 96-99.

[24] Gu, Y., Xu, G., Guo, Z., and Wang, S. (2012). Esterification research on a bio-oil model compounds system with an optimal solid acid catalyst. Advanced Materials Research, 383-390 (2012), 1144-1149.

[25] Zhang, Z., Sui, S., Tan, S., Wang, Q., and Pittman Jr. C. U. (2013). Catalytic conversion of bio-oil to oxygen containing fuels by simultaneous reactions with 1-butanol and 1octene over solid acids: Model compound studies and reaction pathways. Bioresource Technology, http://dx.doi.org/10.1016/j.biortech.2012.11.060.

[26] Yang, X., Chatterjee, S., Zhang, Z., Zhu, X., and Pittman, Jr. C. U. (2010). Reactions of phenol, water, acetic acid, methanol, and 2-hydroxymethylfuran with olefin and models for bio-oil upgrading. Industrial and Engineering Chemistry Research, 49 (2010).20032013. 
[27] Gunawan, R., Li, X., Larcher, A., Hu, X., Mourant, D., Chaiwat, W. and Wu, H. (2012). Hydrolysis and glycosidation of sugars during the esterification of fast pyrolysis, Fuel, 95(2012), 146-151.

[28] Zhang, Q., Chang, J., Wang, T. and Xu, Y. (2006). Upgrading bio-oil over different solid catalysts. Energy \& Fuels 2006, 20, 2717-2720.

[29] Meng, J., Park, J., Tilotta, D., and Park, S. 2012. The effect of torrefaction on the chemistry of fast -pyrolysis bio-oil. Bioresource Technology, 111(2012), 439- 446

[30] Van der Stelt, M. J. C., Gerhauser, H., Kiel, J. H. A., and Ptasinski, K. J. 2011. Biomass upgrading by torrefacton for the production of biofuels: A review. Biomass and Bioenergy, 35(2011), 3748- 3762.

[31] Boateng, A. A., and Mullen, C. A. 2013. Fast pyrolysis of biomass thermally pretreated by torrefaction. Journal of Analytical and Applied Pyrolysis. 100(2013), 95- 102.

[32] Dong, C., Zhang, Z., Lu, Q., and Yang, Y. (2012). Characteristics and mechanism study of analytical fast pyrolysis of poplar wood. Energy Conversion and Management, 57(2012), 49-59.

[33] Demirbas, A. (2007). The influence of temperature on the yields of compounds existing in bio-oils obtained from biomass samples via pyrolysis. Fuel Processing Technology, 88(2007), 591-597.

[34] Westerhof, R. J. M., Kuipers, N. J. M., Kersten, S. R. A., and van Swaaij, W. P. M. (2007). Controlling the water content of biomass fast pyrolysis oil. Industrial and Engineering Chemistry Research, 46 (2007). 9238-9247.

[35] Garcia-Perez, M., Wang, S. X., Shen, J., Rhodes, M. J., Tian, F., Lee, W., Wu, H. C., and Li, C. (2008). Fast pyrolysis of Mallee woody biomass: Effect of temperature on the yield and quality of pyrolysis products. Industrial and Engineering Chemistry Research, 47 (2008), 1846-1854. 
[36] Garcia-Perez, M., Wang, S., Shen, J., Rhodes, M., Lee, W. J., Li, C. Z. (2008). Effects of temperature on the formation of lignin-derived oligomers during the fast pyrolysis of Mallee woody biomass. Energy \& Fuels, 22 (3), 2022-2032.

[37] Azeez, A. M., Meier, D., Odermatt, J. and Willner, T. (2010). Fast pyrolysis of African and European lignocellulosic biomasses using Py-GC/MS and fluidized bed reactor. Energy \& Fuels 2010, 24, 2078-2085.

[38] Westerhof, R. J. M., Brilman, D. W. F., Garcia-Perez, M., Wang, Z., Oudenhoven, S. R. G., van Swaaij, W. P. M. and Kersten, S. R. A. (2011). Fractional condensation of biomass pyrolysis vapours. Energy \& Fuels 2011, 25, 1817-1829.

[39] Oasmaa, A., Sipila, K., Solantausta, Y. and Kuoppala, E. (2005). Quality improvement of pyrolysis liquid: Effect of light volatiles on the stability of pyrolysis liquids. Energy \& Fuels 2005, 19, 2556-2561.

[40] Chang, C. C., Wu, S. R., Lin, C. C., Wan, H. P. and Lee, H. T. (2012). Fast pyrolysis of biomass in pyrolysis gas: fractionation of pyrolysis vapors using a spray of bio-oil. Energy \& Fuels 2012, 26, 2962-2967.

[41] Pollard, A. S., Rover, M. R., and Brown, R. C. (2012). Characterization of bio-oil recovered as stage fractions with unique chemical and physical properties. Journal of Analytical and Applied Pyrolysis. 93(2012), 129-138.

[42] Tzanetakis, T., Ashgriz, N., james, D. F., and Thomson, M. J. (2008). Liquid fuel properties of a hardwood derived bio-oil fraction. Energy \& Fuels, 22(2008), 2725-2733.

[43] Chen, T., Deng, C., and Liu, R. (2010). Effect of selective condensation on the characterization of bio-oil from pine sawdust fast pyrolysis using a fluidized bed reactor. Energy \& Fuels, 24(2010), 6616-6623.

[44] Guo, X., Wang, S., Guo, Z., Liu, Q., Luo, Z and Cen K. (2010). Pyrolysis characteristics of bio-oil fractions separated by molecular distillation. Applied Energy, 87(2010), 28922898. 
[45] Tumbalam Gooty, A. 2012. Fractional condensation of bio-oil vapors. University of Western Ontario - Electronic Thesis and Dissertation Repository. Paper 979. http://ir.lib.uwo.ca/etd/979 


\section{Chapter 1}

\section{Quantification of phase separation of hardwood derived bio- oil and changes of physical and chemical compositions before and after phase separation}

\subsection{Introduction}

Pyrolysis is a thermochemical process that converts solid biomass into a liquid fuel, which is called bio-oil [1]. At room temperature, bio-oil is often, initially, a single phase, dark, viscous liquid that contains more than 300 chemical components [1-4].

However, as it was explained in the 'Introduction' (page xiv), when compared to conventional liquid fuels, bio-oil has several undesired properties such as high viscosity, high acidity, high molecular weight, instability and phase separation upon aging, which means that properties, such as viscosity, change with storage time and temperature [1-4]. Further, the high oxygen and water contents of pyrolysis oil result in a lower energy density than conventional fuel oils [5, 6]. Amongst all the above deleterious properties, instability is one of the biggest challenges because it not only changes bio-oil properties such as viscosity, but also induces phase separation that prevents the application of bio-oil as a fuel. Therefore, bio-oil needs further stabilization and upgrading before it can be used as a fuel in existing engines [1]. According to Batts and Fathoni [7], the term "fuel stability" characterizes the general resistance of a fuel to change. At ambient conditions, it can refer to "storage stability", that is, the ability of a fuel to remain in storage over an extended period of time without appreciable deterioration. However, in most of the past literature, the stability of pyrolysis liquids was measured as an absolute increase in its viscosity during typical storage or by using an accelerated aging test [2- 4]. In addition to increased viscosity, storage (especially at elevated temperatures) has resulted in increasing water content [7], increasing molecular weight [1-4, 8] and phase separation [1].

The literature [1-4] indicates that the whole picture of fuel stability is very complex and that there is likely no single explanation for all the phenomena associated with bio-oil degradation. It 
has been observed during aging that different unsaturated and reactive components interact by means of polymerization, esterification, acetalization, oxidization or dimerization to form larger molecules and consequently cause changes in physical properties, such as viscosity [1- 4]. To prevent these undesired aging reactions, physical and chemical upgrading methods have been investigated. They include solvent addition [8-15], emulsification with diesel fuel [16-20], deoxygenation using zeolite catalysts and catalytic hydrotreating.

Hydrotreating is considered to be a very expensive and energy consuming process. It also reportedly causes phase separation [21] and drastically increases the viscosity of the organic phase [1]. Deoxygenation processes based on catalytic hydrotreatment or catalytic cracking not only significantly reduce the liquid yield, but are also capital intensive [5]. Only a very small fraction of bio-oil is soluble in typical diesel fuels [1]. However, recently, many efforts have been directed to producing an emulsion of bio-oil with diesel [16-20]. In most cases, there is an immediate phase separation between the bio-oil and diesel and, therefore, an emulsifying agent needs to be added at high concentration [16-20] to stabilize the emulsion, resulting in a high fuel cost [16]. Udomsap et al. [20] report that up to $40 \%$ of surfactant needs to be added to emulsify bio-oil with oil with a proportion of $40 \%$. Even with alcohols, a very high concentration of alcohol is required for proper emulsification [17].

Additives, especially, low viscosity alcohols, can reduce both the initial viscosity of bio-oil and its increase during aging $[2,3,22,23]$. Literature shows that beneficial chemical reactions occur between bio-oil and the solvent [1].

Oasmaa [24] developed the concentration method, which removes part of the water and light volatiles and replaces them with alcohols can improve the quality (viscosity, flash point and stability) of bio-oil. In this case, a fraction of the carboxylic acids, aldehydes and ketones are removed along with water. Zuo-gang et al. [25] also improved the quality of bio-oil by removing acid compounds from the bio-oil by molecular distillation.

As a result of ongoing chemical reactions, polymerization processes, and initial high water concentrations, during aging, bio-oil spontaneously separates into two phases, i.e., the more polar aqueous phase, which consist mainly of water soluble compounds, and the non polar viscous bottom phase, which consists of lignin extractives [2, 26-27]. Previous studies have been 
conducted separately for upper and bottom bio-oil layers after phase separation by gravity or by centrifugation [27]. Some work has also been done to extract valuable chemical and fuels from bio-oil by effective phase separation through salt addition [26, 28]. Scholez et al. [29-30] induced phase separation through water extraction, adding bio-oil to cold water, to extract pyrolytic lignin from bio-oil. Since the water insoluble fraction is high in phenolics compounds, $\mathrm{Xu}$ et al. [31] investigated the possibility of using this fraction of rice husk bio-oil for the production of novolac resins.

Boucher et al. [32] have shown that adding methanol is useful for delaying the phase separation of vacuum pyrolysis softwood bark bio-oil. However, most of the recent upgrading studies use a high concentration of solvent, reaching more than $50 \%$ of the mixture [8-12].

The purpose of the current research is to study and identify the changes in chemical composition physical properties of bio-oil before and after the phase separation. Then, the research is extended to investigate the effect of low concentrations of alcohols on aging and specifically on phase separation. The ultimate objective is to identify the most suitable stabilizer for avoiding phase separation and the minimum required amount of stabilizer that needs to be added to prevent phase separation during aging of bio-oil for a given period of time. The effect of stabilizer on chemical composition is investigated.

\subsection{Materials and methods}

\subsubsection{Chemicals and materials}

Fast pyrolysis bio-oil was purchased from the Biomass Technology Group (BTG), The Netherlands. Bio-oil is a single phase liquid at room temperature, with $21.8 \mathrm{wt} \%$ water content. butanol, ethanol, isopropanol and propanol were purchased from the Sigma Aldrich Company.

\subsubsection{Quantification of phase separation due to aging of bio-oil}

A set of pre-weighed bio-oil samples $(10 \mathrm{~g})$ was sealed in glass tubes and kept at $80{ }^{\circ} \mathrm{C}$ in a constant temperature water bath for different periods of time. At hourly intervals, one sample was taken out of the bath, cooled down to room temperature and the weight of the aged bio-oil was measured to determine the weight of volatile losses during aging. In each case, the weight 
loss of the aged bio-oil was less than $2.0 \mathrm{wt} \%$. Then, the samples were centrifuged in a Marathon 2100 centrifuge (Fisher Scientific) for 20 minutes at $5000 \mathrm{rpm}$ and checked for phase separation. Once the first signs of phase separation appeared, the sealed sample was stored at $4{ }^{\circ} \mathrm{C}$ in a refrigerated cabinet for 20 hours. After 20 hours, the top and bottom phases were separated by decanting and each phase was weighed. The water content of the top and bottom phases was measured using a Mettler Toledo volumetric Karl Fischer titrator using AquaStar CombiSolventKeto as the titrant. The higher heating value (HHV) of both top and bottom phases was measured using a bomb calorimeter (IKA C200). The same steps were followed for other periods of aging and a different sample was used for each time. The top and bottom phases were analysed in a coupled GC-MS/FID (flame ionization detector) to determine their chemical compositions.

\subsubsection{Chemical composition of top and bottom phases with aging time}

Gas chromatography - mass spectrometry

The samples from top and bottom phases were analysed by gas chromatography-mass spectrometry (GC-MS) coupled with a flame ionization detector (FID). The mass spectrometer was used to identify the various compounds while the flame ionization detector was used to determine their concentrations. The GC-MS/FID is a Shimadzu GCMS-QP2010 plus, equipped with auto sampler/injector and a capillary column (RTX-1701) of $30 \mathrm{~m}$ x $0.25 \mathrm{~mm}$ i.d. (film thickness: $0.25 \mu \mathrm{m}$, column flow: $0.75 \mathrm{~mL} / \mathrm{min}$, carrier gas: helium, maximum temperature: $280^{\circ} \mathrm{C}$ ). Samples were mixed with a 1-dodecanol internal standard solution at a 1:1 ratio, diluted with methanol at a 1:22 ratio, and filtered using $0.2 \mu \mathrm{m}$ pore size TEFLON filters. Then, $1 \mu \mathrm{L}$ of sample was injected with a split ratio of 1:20 while the column was maintained at $45{ }^{\circ} \mathrm{C}$ for 3 minutes before being heated to $220{ }^{\circ} \mathrm{C}$ at a rate of $5{ }^{\circ} \mathrm{C} / \mathrm{min}$, then the column was heated to $280{ }^{\circ} \mathrm{C}$ at a rate of $30{ }^{\circ} \mathrm{C} / \mathrm{min}$, and held for $3 \mathrm{~min}$. The identification of the peaks in the chromatogram was based on the comparison with standard spectra and/or on the retention time of known standards injected. Quantification of each group of compounds was done by manual integration of single ion chromatograms. The Appendix A shows the calculation of $3 \mathrm{hrs}$ of aging data in Figure 1.2.

\subsubsection{Prevention of phase separation of bio-oil through solvent addition}


Butanol, ethanol, isopropanol or propanol was individually added in different concentrations to bio-oil samples and the sealed samples were kept at $80{ }^{\circ} \mathrm{C}$ in a water bath. Every one hour period, the samples were cooled down, centrifuged for 20 minutes at $5000 \mathrm{rpm}$ and checked for phase separation. These steps were followed until the samples became phase separated. The time taken for phase separation to happen was recorded.

\subsubsection{Chemical composition of bio-oil during aging with Isopropanol as a solvent}

As shown below, isopropanol is the most effective of the tested solvents in preventing phase separation during long storage periods. The changes in chemical composition of the bio-oil with aging in presence of isopropanol (at 10 and $20 \mathrm{wt} \%$ concentrations) were, therefore, investigated. Sealed samples of BTG bio-oil and $10 \mathrm{wt} \%$ isopropanol were kept at $80{ }^{\circ} \mathrm{C}$ in a water bath for 17 days and samples were taken for GC-MS/FID analysis at 24 hours interval at the beginning and at 2-3 days intervals later on. Once phase separation had occurred, the top and bottom phases were separated by decanting and samples were taken for GC-MS/FID analysis. The GC-MS/FID analysis and peak area calculations were done according the method that is presented in section 2.3 .

\subsubsection{Quantification of phase separation by water titration}

Different percentages of water were added to different sets of bio-oil samples. The samples were well mixed, sealed and allowed to settle for 5 days at room temperature (because it was observed that more watery samples took a longer time to settle). After settling, the top and bottom phases were separated by decanting and the water content of each phase was measured using the Karl Fischer titrator.

\subsubsection{Higher heating value}

HHV was measured with the bomb calorimeter for each aged sample and both top and bottom phases in case of phase separation.

\subsection{Results and discussion}

\subsubsection{Is phase separation effective?}


Figure 1.1 shows the composition of top and bottom phases 6 hours after the initiation of phase separation. It is observed that the top phase contains a higher percentage of water and sugars and a lower share of phenolics when compared to the bottom phase. However, the concentrations of those components in both phases are still significant and the other components are also distributed in both phases. Therefore, the phase separation is not an effective method to segregate one or more of the component groups.

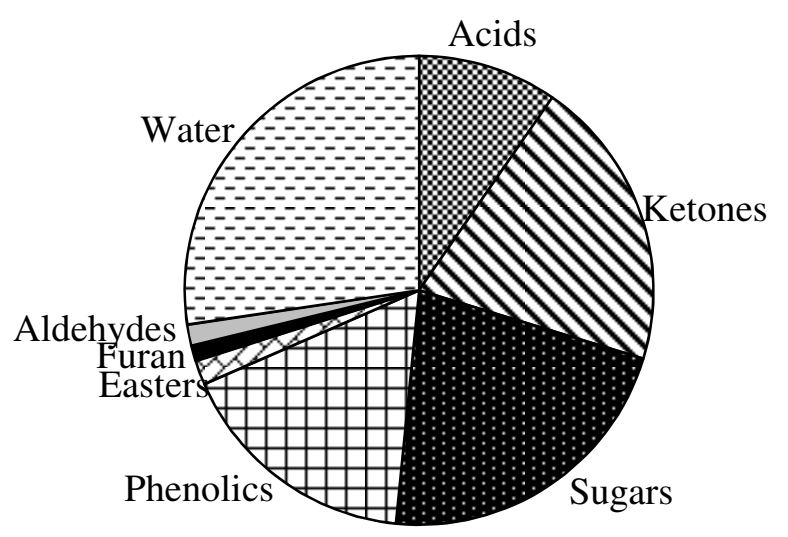

(a)

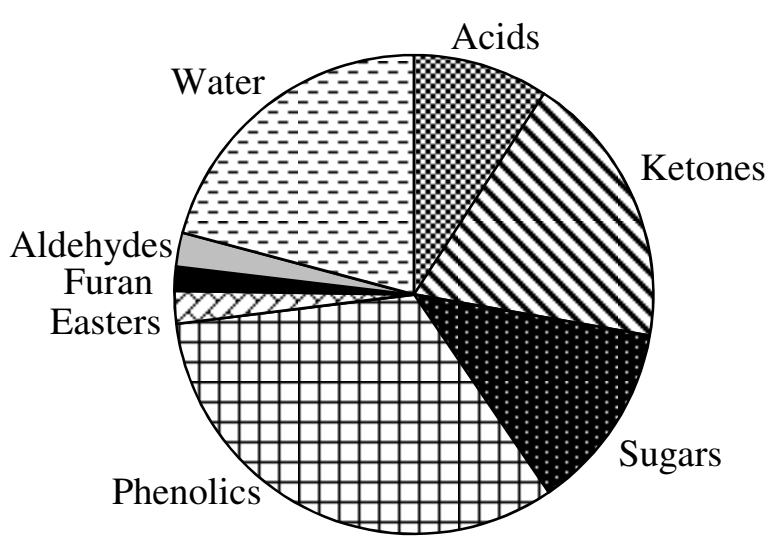

(b)

Figure 1.1: The composition of top and bottom phases after phase separation occurs (at 24 hours). (a) top phase. (b) bottom phase.

\subsubsection{What triggers phase separation?}

Figure 1.2 shows the evolution of chemical composition of aged bio-oil during the accelerated aging process before phase separation occurs. The behaviour of a sample of BTG bio-oil during aging shows that, at first, some reactions occur relatively rapidly: for example, the results show that, after only 6 hours, the esters concentration has increased by about $50 \%$. After this initial period, the concentration of all the component groups that are observed in GC-MS/FID decreases with time. Since GC-MS can identify only the light compounds in the oil, this gives an indication that some of the components from each group might be disappearing from the light fraction through polymerization or condensation reactions. 


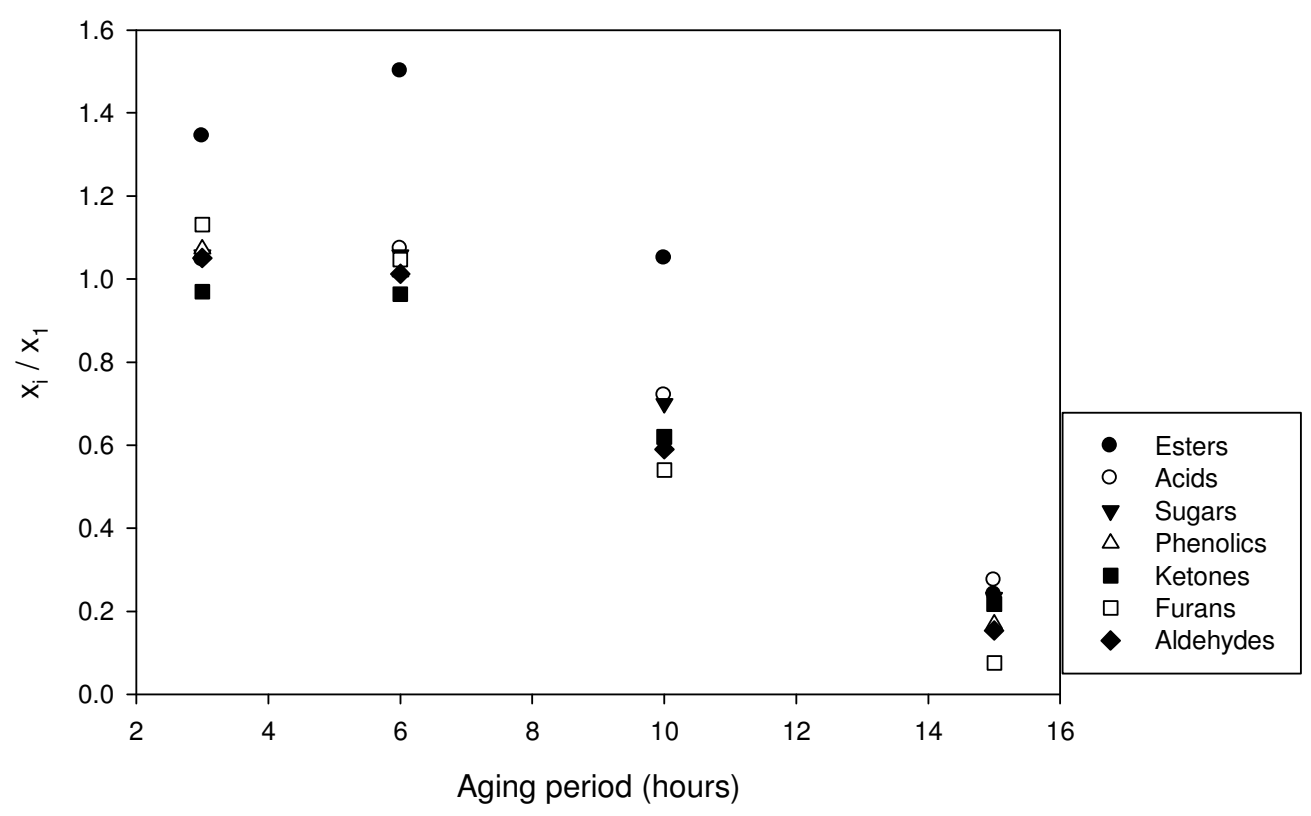

Figure 1.2: Change in chemical composition of BTG bio-oil during aging at $80^{\circ} \mathrm{C}$.

$$
\begin{aligned}
& \mathrm{x}_{1}=\frac{\text { Peak area of GC }- \text { FID for component } k \text { at time } 1}{\text { Peak area for internal standard at time } 1} \\
& \mathrm{x}_{i}=\frac{\text { Peak area of GC }- \text { FID for component } k \text { at time } i}{\text { Peak area for internal standard at time } i}
\end{aligned}
$$

\subsubsection{What happens after the phase separation occurs?}

Figure 1.3 shows the composition of bio-oil before phase separation and combined values of top and bottom phases after phase separation. Since the weight proportion of the bottom phase continuously increases with time, the compositions are combined based on their weight percentages at the each time period. Figure 1.3 shows that phase separation does not have a dramatic effect on the trends observed before phase separation, with the exception of acids, whose concentration increases sharply upon phase separation and then remains approximately constant. 


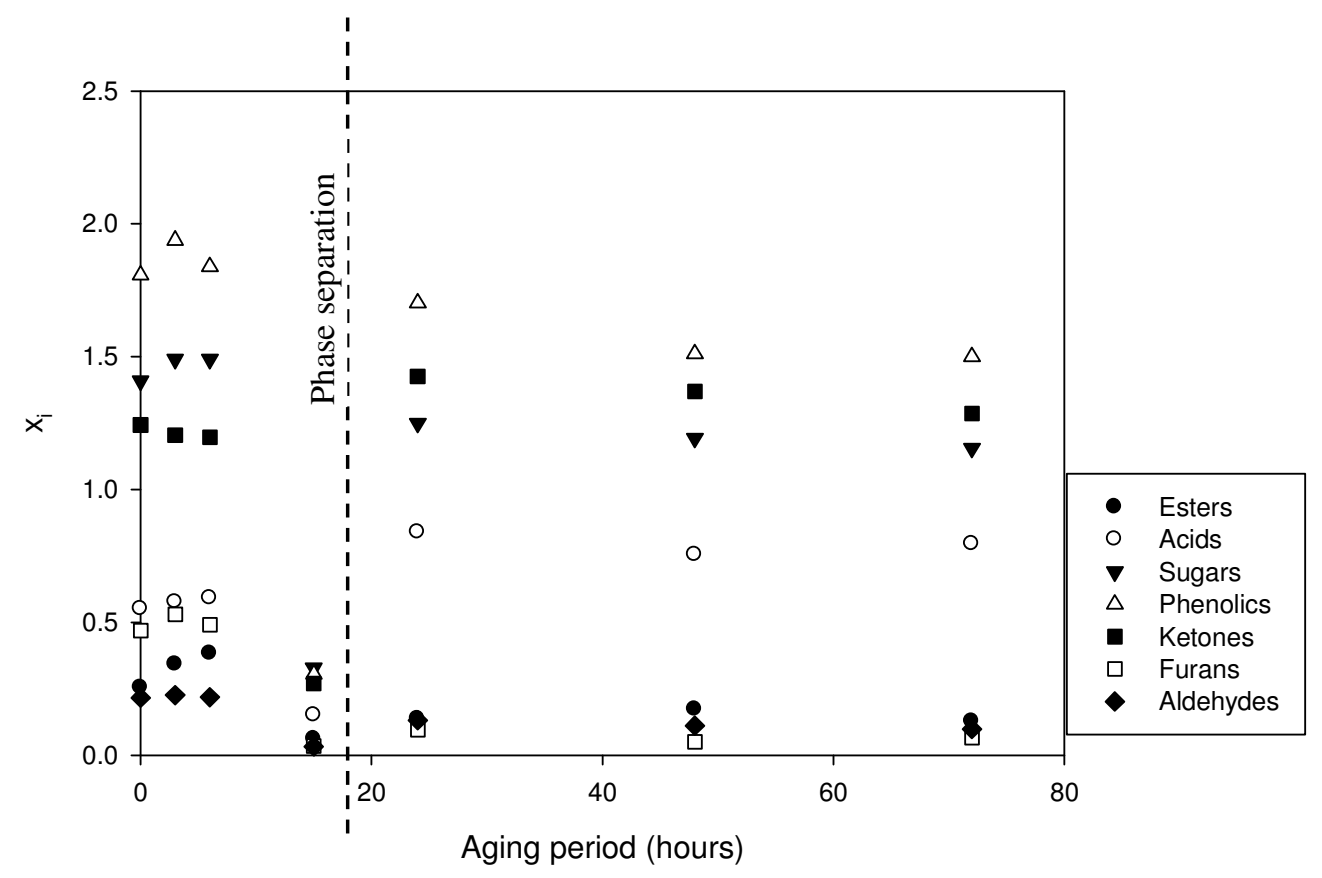

Figure 1.3: Chemical composition of bio-oil before phase separation and combined valued for top and bottom phases after the phase separation occurred (values are combined based on their weight $\%$ at respective aging time).

Oasmaa et al. [33] show that the increase in water-insoluble compound is paired with the reduction in carbonyl compounds, such as esters, carboxylic acids, ketones and aldehydes, and this is correlated to the increase in molecular weight during aging. They show that the change in carbonyl compounds is due to reactions of aldehydes and ketones during storage, whose reaction products end up in the water-insoluble fraction. Similarly, Kim et al. [34] concluded that the decrease in concentration of most of the low molecular weight components in bio-oil during aging results from their chemical involvement in reactions with pyrolytic lignin. Their study also found that these reactions increase both the yield of pyrolytic lignin and the average molecular weight over the aging period [34]. 


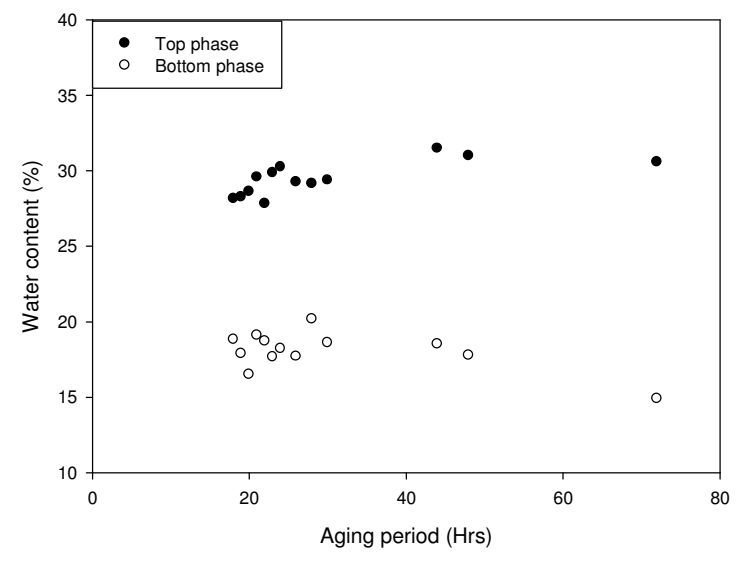

(a)

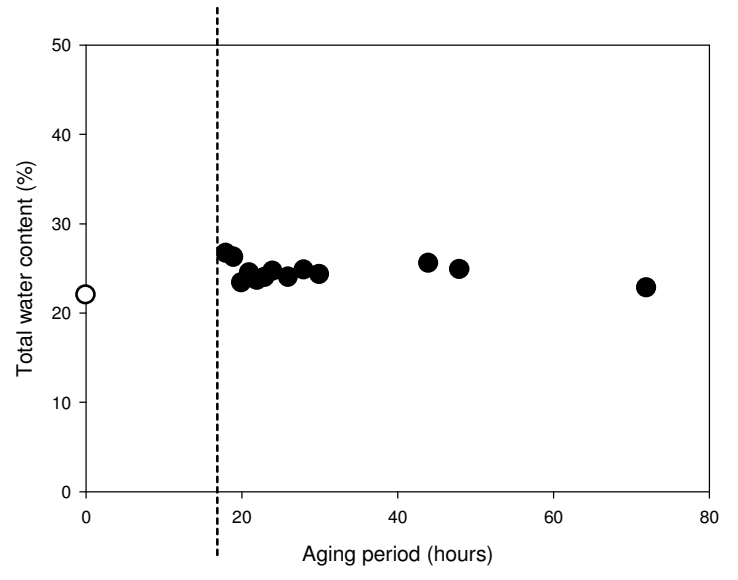

(b)

\section{Figure 1.4: Water content of (a) Top and bottom phases of aged, centrifuged and settled bio-oil, and (b) the system (by water balance).}

Phase separation can be a result of the formation of water or heavy compounds as a by product or as a result of polymerization and condensation reactions during aging [35]. In this study, as shown in Figure 1.4 (b), during aging of BTG bio-oil at $80{ }^{\circ} \mathrm{C}$, for the first three days the increase in the total water amount is hardly noticeable. Boucher et al. [32] have also noticed that there was no significant increase or decrease of total water content during accelerated aging of bio-oil derived from softwood bark. Similarly, Kim et al. [34] found the same result during aging of poplar wood bio-oil at $23{ }^{\circ} \mathrm{C}$ for a 10 weeks period. However, after phase separation, the water content of the top and bottom phases was significantly different at any given time (Figure 1.4a). Even though the water content of the bottom phase slightly declined with time, this was due primarily to the growth with time in the amount of bottom phase through the migration of compounds other than water from the top phase to the bottom phase.

\subsubsection{What happens when solvents are added to bio-oil?}

Phase separation during storage can be prevented by adding the proper solvent. The impact of the addition of low concentrations (up to $10 \mathrm{wt} \%$ ) of butanol, ethanol, isopropanol and propanol on the occurrence of phase separation is shown in Figure 1.5. Obviously the phase stability increases with increased proportion of additives. Isopropanol is the most effective of the four tested additives, since it keeps the oil in a single phase for the longest duration at $80{ }^{\circ} \mathrm{C}$. For 
example, $10 \%$ addition of isopropanol prevents phase separation for 13 days at $80{ }^{\circ} \mathrm{C}$. In the same way, Boucher et al. [32] showed that $15 \%$ addition of methanol will increase the phase stability of bio-oil.

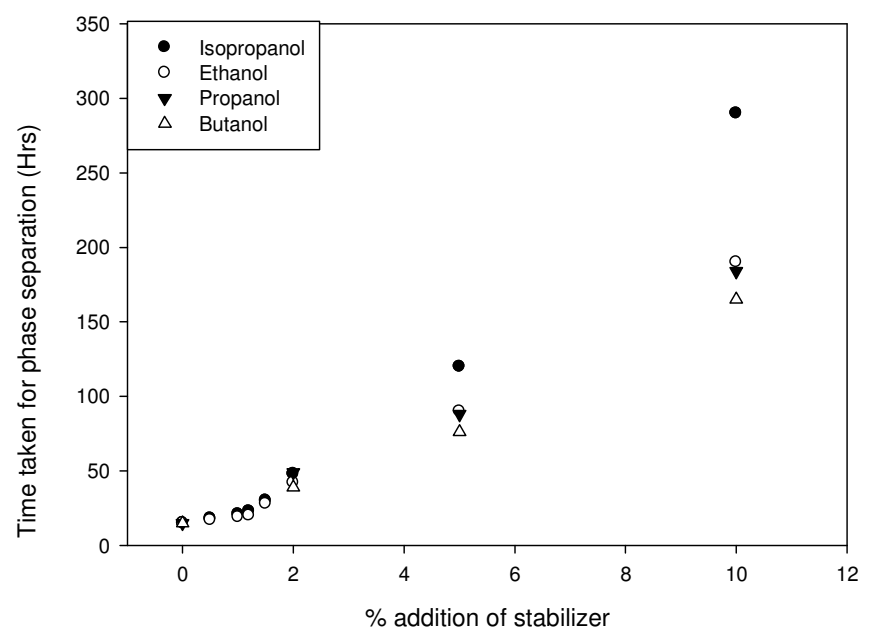

\section{Figure 1.5: Time taken for phase separation to occur at different percentage of stabilizers, under accelerating aging conditions $\left(\right.$ at $\left.80^{\circ} \mathrm{C}\right)$.}

There are two possible explanations for the inhibition of phase separation observed with the addition of low molecular weight alcohol: the alcohol could increase the mutual solubility of the polar and non-polar bio-oil components or, alternately, alcohols may react with some of the biooil components. The change in chemical composition of bio-oil treated with $10 \mathrm{wt} \%$ of isopropanol is shown in Figure 1.6. Prior to phase separation, the major changes are the decline in phenolics, ketones and aldehydes and the increase of esters. Similar results have been observed in many previous studies $[2,3,33,36]$. The acid content is slightly decreased. After 13 days of aging at $80{ }^{\circ} \mathrm{C}$, the aqueous phase, which is rich in sugars, and the organic phase, which is rich in phenolics, separated. The decrease in phenolics, ketones and aldehydes might have changed the mutual solubility of the bio-oil components, or the formation of high molecular weight components through polymerization or condensation reactions might have reduced their mutual solubility. Diebold [1] also argues that as the bio-oil composition changes during aging, the mutual solubility of the components changes to make phase separation more likely. Diebold also argues that the increasing difference in polarity among the compounds in the aged bio-oil increases the tendency for phase separation [1]. For example, esterification converts highly polar 
organic acid and alcohol molecules into esters with relatively low polarity and extremely polar water. The formation of acetals shifts the composition away from acetaldehyde hydrates, releasing the water of hydration and the water formed with the acetal. Acetals are in the relatively nonpolar family of ethers.

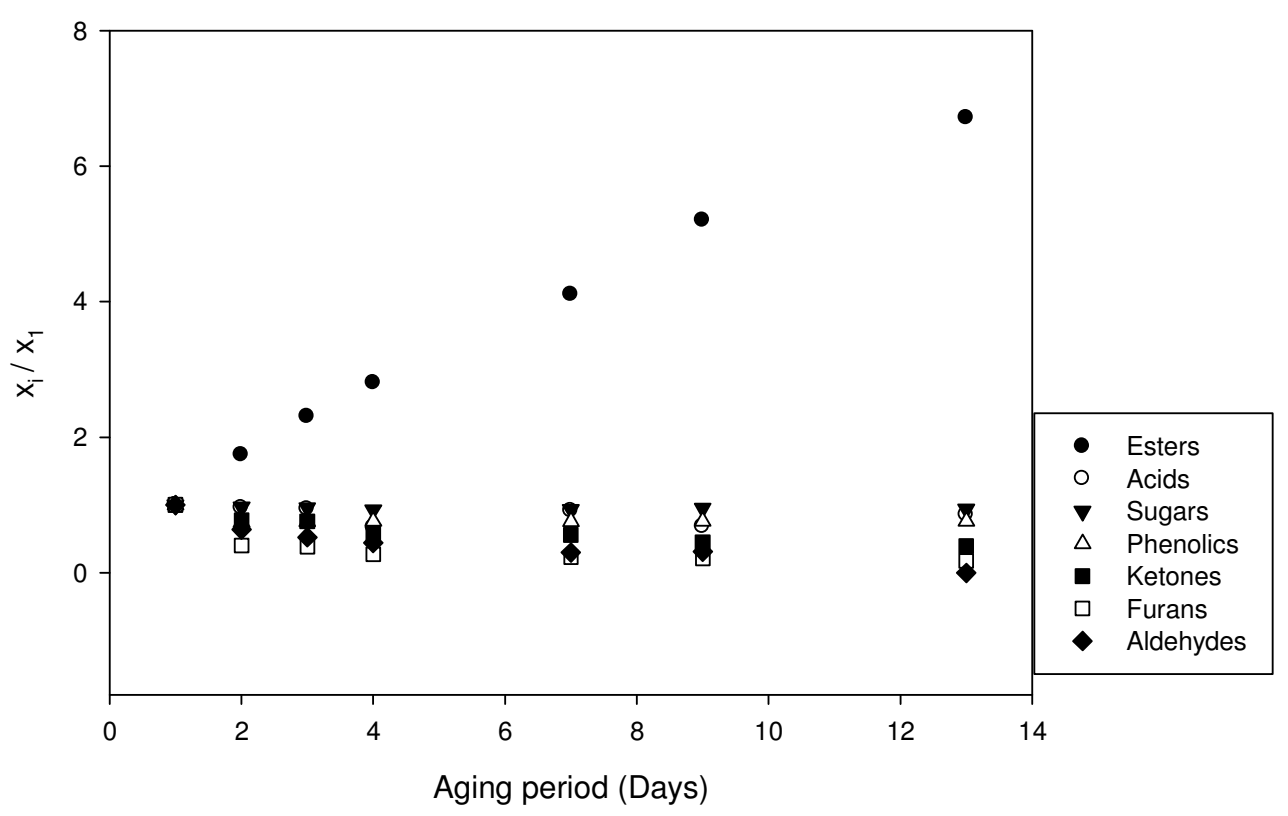

Figure 1.6: Change in chemical composition of BTG bio-oil with $10 \%$ isopropanol during aging at $80^{\circ} \mathrm{C}$.

$$
\begin{aligned}
& \mathrm{x}_{1}=\frac{\text { Peak area of GC }- \text { FID for component } k \text { at time } 1}{\text { Peak area for internal standard at time } 1} \\
& \mathrm{x}_{i}=\frac{\text { Peak area of GC }- \text { FID for component } k \text { at time } i}{\text { Peak area for internal standard at time } i}
\end{aligned}
$$

The model compound study by Hu et al. [34] shows that phenolic compounds (phenol, guaiacol and vanillin etc.) are reactive in an acidic environment. This is confirmed by the decrease in total phenolic compounds observed in this study. Qu et al. [37] concluded that the majority of carbohydrates and sugars in the bio-oil come from the cellulose fraction of biomass, while the majority of phenolics come from the lignin fraction. They also found out that the hemicellulose is the fraction which mainly contributes towards the acid, ketone and aldehydes contents of the bio-oil [37]. 


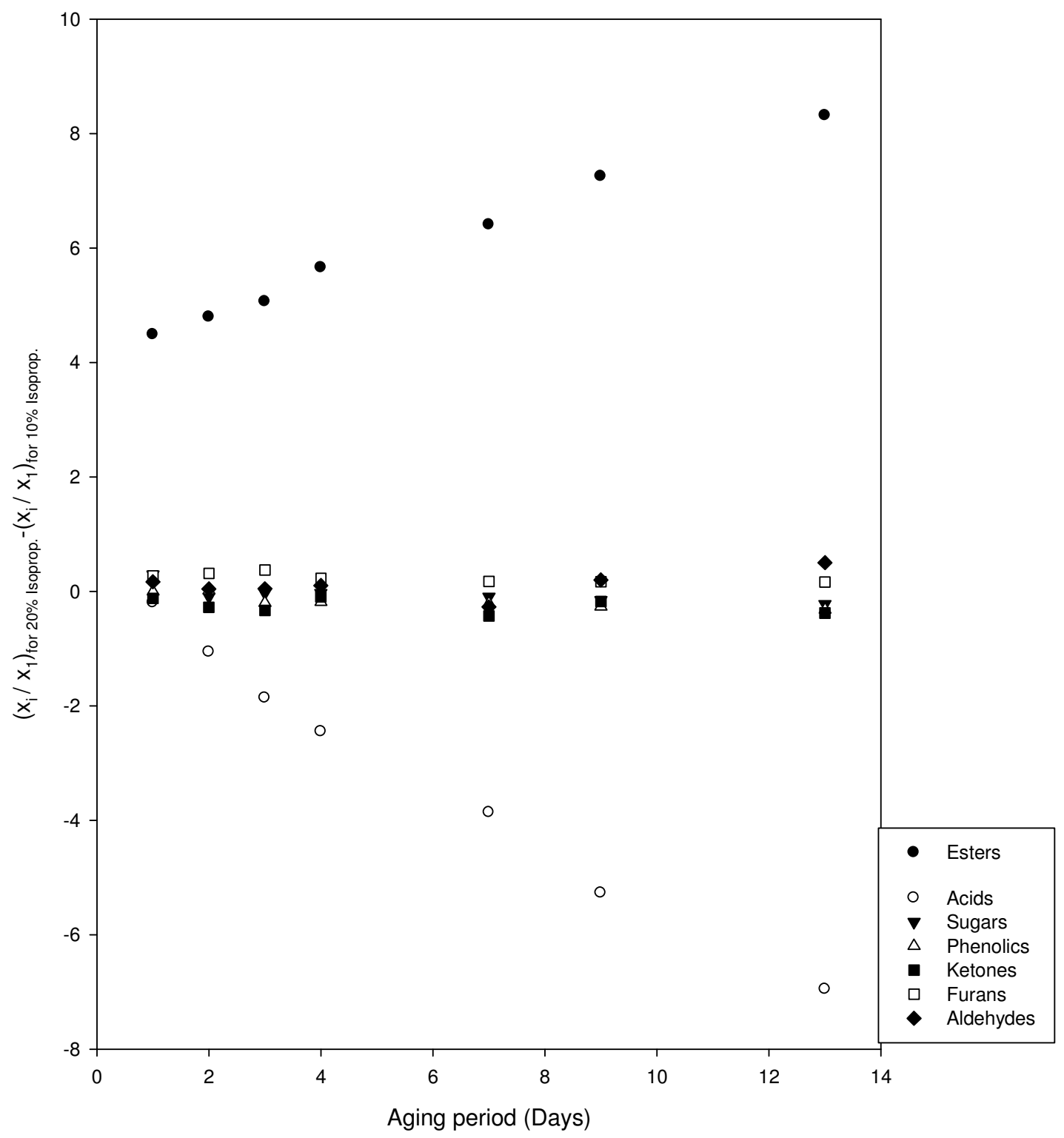

Figure 1.7: The difference of chemical composition of BTG bio-oil with $20 \%$ Isopropanol and $10 \%$ isopropanol during aging at $80{ }^{\circ} \mathrm{C}$.

$$
\begin{aligned}
& \mathrm{x}_{1}=\frac{\text { Peak area of GC }- \text { FID for component } k \text { at time } 1}{\text { Peak area for internal standard at time } 1} \\
& \mathrm{x}_{i}=\frac{\text { Peak area of GC }- \text { FID for component } k \text { at time } i}{\text { Peak area for internal standard at time } i}
\end{aligned}
$$


Figure 1.7 shows the change in composition of each component group when the isopropanol concentration is increased from $10 \%$ to $20 \%$. The proportion of esters continues to increase and acids to decrease. There is no measurable impact on ketones, furans and aldehydes. It can be concluded from these results that the addition of polar solvents (isopropanol in this case) not only changes the mutual solubility of components but also changes the chemical composition through reactions such as the esterification of carboxylic acids.

\subsubsection{What happens when water is added to bio-oil?}

It is well known that in the presence of excess water, bio-oil is separated into two phases, i.e., the aqueous top phase and the organic bottom phase. More of the water is accumulated into the aqueous phase whereas the bottom phase contains less water [26- 27]. Water extraction has been widely used as the first step for recovering renewable chemicals from bio-oil [38]. Figure 1.8 shows the water content of top and bottom phases when water titration is performed as explained in section 1.2.6. The oil is phase separated when the total water content in the system (the mixture of water and bio-oil) reaches $23.2 \mathrm{wt} \%$. By adding more water to the system, the top phase is continuously diluted while the water content of the bottom phase remains almost constant.

In a previous study, Vitasari et al. [38] concluded that the addition of water to bio-oil from forest residues and pine will dilute the aqueous phase while keeping the water content in the organic phase nearly constant. This was exemplified in our results as well. However, Oasmaa and Czernik [5] stated that the amount of water that can be dissolved in oil before phase separation occurs depends on the feedstock and their paper demonstrated a similar phase diagram of water and bio-oil system, of which, the phase separation of birch, pine and poplar wood bio-oil takes place at 20, 23-25, $31 \mathrm{wt} \%$ of water, respectively [5]. In the present study, the hardwood derived BTG bio-oil is phase separated at a water content very close to that of pine wood derived bio-oil in their study. 


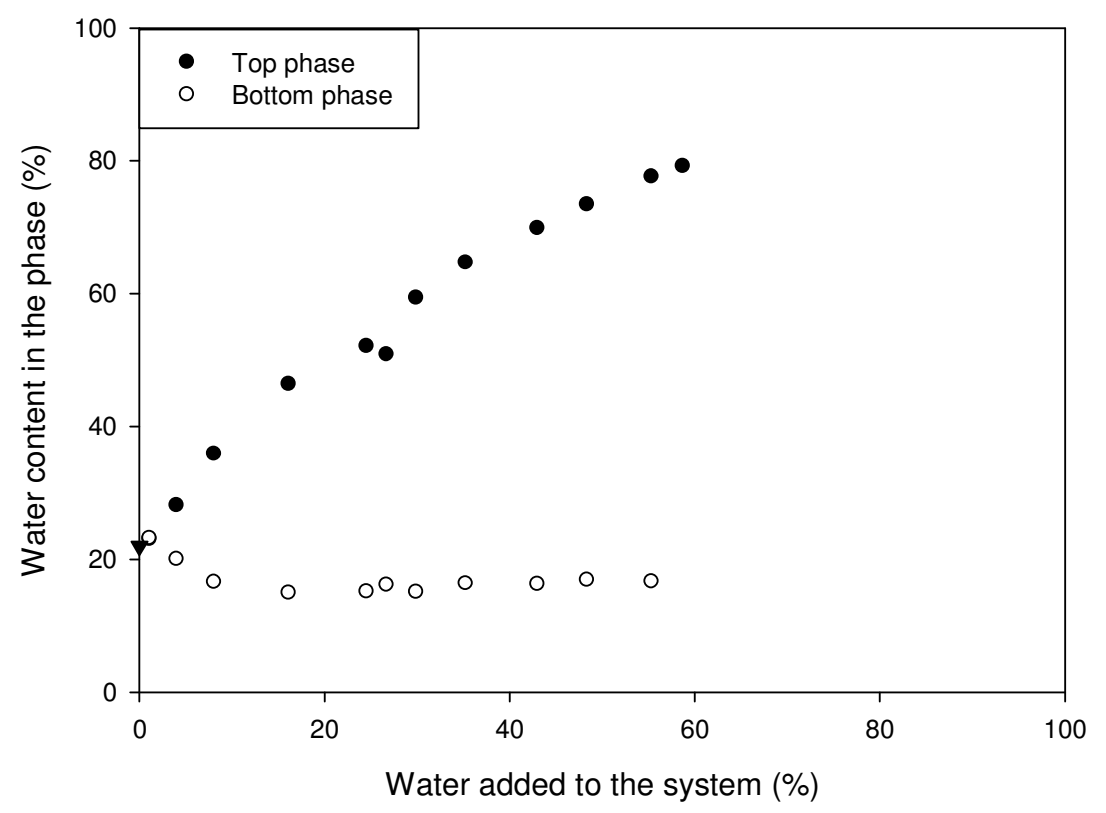

Figure 1.8: The variation of water content in the top and bottom phases of bio-oil vs. water content in the system.

\subsubsection{Change of the higher heating value (HHV) of bio-oil with isopropanol added as a solvent}

Figure 1.9 shows the evolution of the higher heating value (HHV) of bio-oil with the addition of $10 \%$ or $20 \%$ isopropanol, as well as the combined values of top and bottom phases based on their weight percentages during aging at $80^{\circ} \mathrm{C}$. The addition of isopropanol prevents the drop in bio-oil HHV that is caused by aging. 


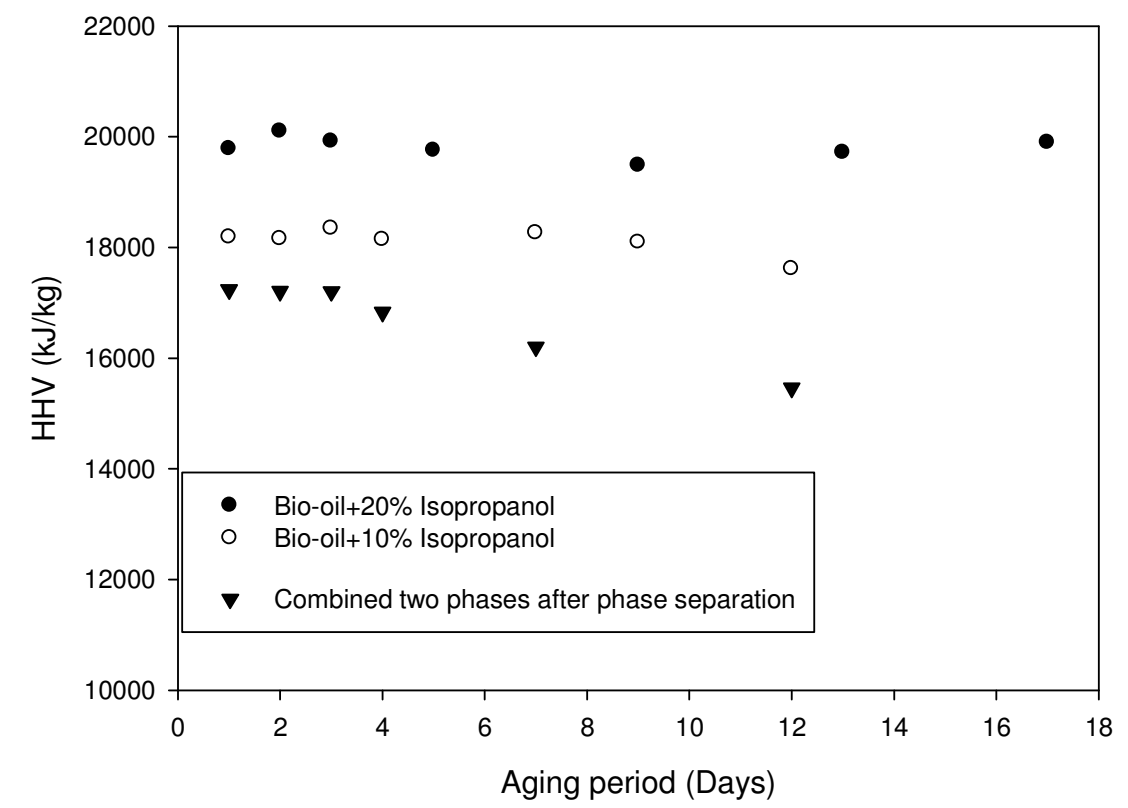

Figure 1.9: Change in HHV of bio-oil with $10 \%$ and $20 \%$ isopropanol and combined top and bottom phases without solvent (values are combined based on their weight $\%$ at respective time of aging).

\subsection{Conclusions}

Natural phase separation of bio-oil or artificial phase separation by water addition is not effective tools to segregate components into two single phases.

During aging of bio-oil at $80{ }^{\circ} \mathrm{C}$, phase separation of hardwood derived bio-oil occurs after about 15 hours. GC-MS analysis shows that some of the components, such as phenolics, sugars, ketones, esters, acids, furans and aldehydes, are disappearing from the light fraction of the bio-oil during accelerated aging. These components may undergo polymerization or condensation with the heavier bio-oil components.

The addition of solvents greatly retards phase separation. Isopropanol is the most suitable alcohol to retard phase separation. The addition of a polar solvent, such as isopropanol, not only 
increases the mutual solubility of the components in bio-oil, but also modifies the chemical composition of the bio-oil through reactions such as esterification.

\subsection{References}

[1] Diebold, J. P. (2000). A review of the chemical and physical mechanisms of the storage stability of fast pyrolysis bio-oils.NREL/SR-570-27613. Colorado, National Renewable Energy Laboratory.

[2] Diebold, J. P. and Czernik, S. (1997). Additives to lower and stabilize the viscosity of pyrolysis oil during storage, Energy \& Fuels 1997, 11, 1081-1091

[3] Oasmaa, A. and Kuoppala, E. (2003). Fast pyrolysis of forestry residue. 3. Storage stability of liquid fuel. Energy \& Fuels 2003, 17, 1075-1084

[4] Czernik, S., Johnson, D. K., Black, S. (1994). Stability of wood fast pyrolysis oil. Biomass and Bioenergy, 7(1-6), 187- 192.

[5] Oasmaa, A. and Czernik, S. (1999). Fuel oil quality of biomass pyrolysis oils- state of the art for the end users. Energy \& Fuels 1999, 13, 914-921.

[6] Demirbas, A. (2007). The influence of temperature on the yield of compounds existing in bio-oils obtained from biomass samples via pyrolysis. Fuel Processing Technology, 88(2007), 591-597.

[7] Batts, B.D. and Fathoni, A.Z. (1991). A literature review on fuel stability with particular emphasis on diesel oil. Energy \& Fuels 1991, 5, 2-21.

[8] Hu, X., Gunawan, R., Mourant, D., Lievens, C., Li, X., Zhang, S. and Chaiwat, W. (2012). Acid-catalysed reaction between methanol and bio-oil from fast pyrolysis of mallee bark. Fuel, 97(2012), 512-522.

[9] Hu, X., Mourant, D., Wang, Y., Wu, L., Chaiwat, W. Gunawan, R., Gholizadeh, M., Lievens, C., Garcia-Perez, M., Li, C. Z. (2013). Acid-catalysed treatment of the mallee 
leaf bio-oil with methanol: Effects of molecular structure of carboxylic acids and esters on their conversion. Fuel Processing Technology, 106(2013), 569-576.

[10] Wang, J. J., Chang, J., Fan, J. (2010). Upgrading of bio-oil by catalytic easterification and determination of acid number for evaluating esterification degree. Energy \& Fuels2010, 24, 3251-3255.

[11] Moens, L., Black, S. K., Myers, M. D. and Czernik, S. (2009). Study of the neutralization and stabilization of a mixed hardwood bio-oil. Energy \& Fuels 2009, 23, 2695-2699.

[12] Li., X., Gunawan, R., Lievens, C., Wang, Y., Mourant, D., Wang, S., Wu, H., GarciaPerez, M. and Li, C. Z. (2011).Simultaneous catalytic esterification of carboxylic acids and acetalisation of aldehydes in fast pyrolysis bio-oil from mallee biomass. Fuel, 90(2011), 2530-2537.

[13] Zhang, Q., Chang, J., Wang, T. and Xu, Y. (2006). Upgrading bio-oil over different solid catalysts. Energy \& Fuels 2006, 20, 2717-2720.

[14] Song, M., Zhong, Z. and Dai, J. (2010). Different solid acid catalysts influence on properties and chemical composition change of upgrading bio-oil. Journal of Analytical and Applied Pyrolysis, 89(2010), 166-170.

[15] Boucher, M. E., Chaala, A. and Roy, C. (2000). Bio-oils obtained by vacuum pyrolysis of softwood bark as a liquid fuel for gas turbine. Part I: Properties of bio-oil and its blends with methanol and a pyrolytic aqueous phase. Biomass and Bioenergy, 19(2000), 337350.

[16] Ikura, M., Stanciulescu, M. and Hogan, E. (2003). Emulsification of pyrolysis derived bio-oil in diesel fuel. Biomass and Bioenergy, 24(2003), 221-232.

[17] Weerachanchai, P., Tangsathitkulchai, C. and Tangsathitkulchai, M. (2009). Phase behaviors and fuel properties of bio-oil-diesel-alcohol blends. World Academy of Science, Engineering and Technology, 56(2009), 387-393. 
[18] Jiang, X., Ellis, N. (2010). Upgrading bio-oil through emulsification with biodiesel: Thermal stability. Energy \& Fuels 2010, 24, 2699-2706.

[19] Yin, Q, Wang, S., Li, X., Guo, Z. and Gu, Y. (2010). Review of bio-oil upgrading technologies and experimental study on emulsification of bio-oil and diesel. International Conference of Optoelectronics and Image Processing 2010, 343-347.

[20] Udomsap, P., Yeinn, Y. H., Hui, J. T. H. and Yoosuk, B. (2011). Towards stabilization of bio-oil by addition of antioxidants and solvents and emulsification with conventional hydrocarbon fuels.International Conference and Utility Exhibition, September 2011, Thailand. http://www.serd.ait.ac.th/icue2011/cd/papers/S11/S\%2011.3.pdf

[21] Venderbosch, R. H., Ardiyanti, A.R., Wildschut, J., Oasmaa, A. and Heeres, H. J. (2009). Stabilization of biomass derived pyrolysis oils. Journal of Chemical Technology and Biotechnology 2010, 85, 674-686.

[22] Qiang, L., Xu-lai, Y. and Xi-feng, Z. (2008). Analysis on chemical and physical properties of bio-oil pyrolysis from rice husk. Journal of Analytical and Applied Pyrolysis. 82(2008), 191-198.

[23] Boucher, M. E., Chaala, A., Pakdel, H. and Roy, C. (2000). Bio-oils obtained by vacuum pyrolysis of softwood bark as a liquid fuel for gas turbine. Part II: Stability and aging of bio-oil and its blends with methanol and a pyrolytic aqueous phase. Biomass and Bioenergy, 19(2000), 351-361.

[24] Oasmaa, A., Sipila, K., Solantausta, Y. and Kuoppala, E. (2005). Quality improvement of pyrolysis liquid: Effect of light volatiles on the stability of pyrolysis liquids. Energy \& Fuels 2005, 19, 2556-2561.

[25] Zuo-gang, G., Shu-rong, W., Ying-ying, Z., Zhong-yang, L. and Ke-fa, C. (2009). Separation of acid compounds for refining biomass pyrolysis oil. Journal of fuel chemistry and technology. 37(1), 49-52. 
[26] Chen, H. W., Song, Q. H., Liao, B. and Guo, Q. X. (2011). Further separation, characterization and upgrading for upper and bottom layer from phase separation of biomass pyrolysis oils. Energy \& Fuels 2011, 25, 4655-4661.

[27] Ba, T., Chaala, A., Garcia-Perez, M., Rodrigue, D. and Roy, C. (2004). Colloidal properties of bio-oils obtained by vacuum pyrolysis of softwood bark.Characterization of water-soluble and water-insoluble fractions. Energy \& Fuels 2004,18, 704-712.

[28] Song, Q. H., Nie, J. Q., Ren, M. G. and Guo, Q. X. (2009). Effective phase separation of biomass pyrolysis oils by adding aqueous salt solutions. Energy \& Fuels 2009, 23, 33073312.

[29] Scholze, B., Hanser, C. and Meier, D. (2001). Characterization of water- insoluble fraction from fast pyrolysis liquids (pyrolysis lignin). Part II: GPC, carbonyl group and C-NMR. Journal of Analytical and Applied Pyrolysis. 58-59(2001), 387-400.

[30] Scholze, B. and Meier, D. (2001). Characterization of water- insoluble fraction from fast pyrolysis liquids (pyrolysis lignin). Part I: PY-GC/MS, FTIR and functional groups. Journal of Analytical and Applied Pyrolysis. 60(2001), 41-54.

[31] Xu, J., Jiang, J., Lv, W., Dai, W. and Sun, Y. (2010). Rice husk bio-oil upgrading by means of phase separation and production of esters from the water phase and novolac resins from the insoluble phase. Biomass and Bioenergy, 34(2010), 1059-1063.

[32] Boucher, M. E., Chaala, A., Pakdel, H. and Roy, C. (2000). Bio-oils obtained by vacuum pyrolysis of softwood bark as a liquid fuel for gas turbine. Part II: Stability and aging of bio-oil and its blends with methanol and a pyrolytic aqueous phase. Biomass and Bioenergy, 19(2000), 351-361.

[33] Oasmaa, A., Korhonen, J. and Kuoppala, E. (2011). An approach for stability measurement of wood-based fast pyrolysis bio-oil. Energy \& Fuels 2011, 25, 3307-3313. 
[34] Kim, T. S., Kim, J. Y., Kim, K. H., Lee, S. and Choi, D. (2012). The effect of storage duration on bio-oil properties. Journal of Analytical and Applied Pyrolysis, 95(2012), 118-125.

[35] Naske, C. D., Polk, P., Wynne, Z., Speed, J., Holmes, W. E. and Walters, K. B. (2012). Postcondensation filtration of pine and cottonwood pyrolysis oil and impacts on accelerated aging reaction. Energy \& Fuels 2012, 26, 1284-1297.

[36] Lievens, C., Mourant, D., He, M., Gunawan, R., Li, X. and Li, C. Z. (2011). An FT-IR spectroscopic study of carbonyl functionalities in bio-oils. Fuel, 90(2011), 3417-3423.

[37] Qu, T., Guo, W., Shen, L., Xiao, J. and Zhao, K. (2011). Experimental study of biomass pyrolysis based on three major components: Hemicellulose, cellulose and lignin. Industrial and Engineering Chemistry Research, 50(2011), 10424-10433.

[38] Vitasari, C. R., Meindersma, G. W. and de Haan, A. B. (2011). Water extraction of pyrolysis oil: The first step for the recovery of renewable chemicals. Bioresource Technology, 102(2011), 7204-7210. 


\section{Chapter 2}

\section{Understanding the chemical reactions that occur during bio- oil aging: a model compound study}

\subsection{Introduction}

Conversion of biomass into bio-oil is one of the most promising methods to replace depleting fossil fuel resources with renewable feedstocks. Pyrolysis is a thermochemical processes that converts solid biomass into a liquid fuel, which is called bio-oil [1]. However, when compared to conventional liquid fuels, bio-oil has several undesired properties such as high viscosity, high acidity, high molecular weight, phase separation and instability, which means that properties, such as viscosity, change with storage time and temperature [1- 4]. Further, the high oxygen (typically 45-50 wt\%) and water contents (typically 15-30 wt\%) of pyrolysis oil result in a lower energy density than conventional fuel oils $[5,6]$. Amongst all the above deleterious properties, the instability is one of the biggest challenges because it not only changes bio-oil properties such as viscosity, but also induces phase separation that prevents the application of bio-oil as a fuel.

Bio-oil is a poorly defined mixture of acids, alcohols, aldehydes, esters, ketones, sugars, phenols, guaiacols, syringols, furans, and multifunctional compounds. The literature [1-4] indicates that the whole picture of fuel stability is very complex and that there is likely no single explanation for all the phenomena associated with bio-oil degradation. It has been observed during aging that different unsaturated and reactive components interact by means of polymerization, esterification, acetalization, oxidization or dimerization to form larger molecules and consequently cause changes in physical properties, such as viscosity [1-4].

Understanding how and why polymerization and other reactions occur is important to develop methods to stabilize or upgrade bio-oil. Significant efforts have been made to understand the polymerization and other chemical reactions between solvents (mainly low molecular mass alcohols) and bio-oil [7, 8, 9, 10]. However, many of these studies use large solvent concentrations, reaching, in some cases, over $50 \%$ [7, 8, 9, 10, 11]. In most studies, the priority 
was to investigate the impact of acid catalyzed esterification on other chemical compounds in the bio-oil [7, 12, 13], and no study addresses the aging process for prolonged periods.

Due to the extreme complexity of bio-oils, the contribution of the main components to the polymerization reactions is not yet fully understood. Therefore, several studies have used model compound mixtures to represent bio-oil [14, 15, 16, 17, 18, 19]. Gunawan et al. [20] and Hu et al. [14] have used bio-oil model compounds to understand the chemical reactions that are happening at elevated temperatures in the range $70-170{ }^{\circ} \mathrm{C}$, but did not investigate what is happening when bio-oil is heated or stored for a prolonged time. Hu et al. concluded that sugars play an important role in polymerization reactions [14]. The anhydrate sugar, levoglucosan, mainly underwent hydrolysis to glucose upon heating up. Glucose is a key compound involved in polymer formation in aqueous media. With the aid of acid, glucose can undergo further dehydration or decomposition into various small compounds that are very reactive [14, 20]. Hu et al. also stated that amongst other sugar derivatives, furans have the highest tendency towards polymerization [14]. As stated earlier, all these model compound studies have been executed to understand the chemical reactions that are occurring within 2 hours of heating times.

The objective of the study is to use model compounds of bio-oil to understand the chemical reactions that occur when accelerated aging occurs over a long period of time. This study aims at developing a better understanding of the roles of the acids, ketones, furans, aldehydes and aromatics compounds in the polymerization/condensation of bio-oil components during aging, and the effects of ethanol and isopropanol on the stabilization of these compounds. A practical objective is to develop appropriate measures to transform reactive compounds into more stable ones.

Acetic acid, hydroxyl acetone, cyclopentanone, furan, 2-propenal have been selected as representative of reactive compounds, and phenol and two substituted phenolic compounds, guaiacol and vanillin, are used to represent the phenolics found in bio-oil. The roles of each compound in chemical reactions are investigated during accelerated aging in a water medium. Ethanol and isopropanol were also added to understand how alcohols stabilize the reactive compounds. 


\subsection{Materials and methods}

\subsubsection{Chemicals and materials}

The chemicals obtained from Sigma Aldrich are of analytical grade and used without any pretreatment.

\subsubsection{Experimental procedure}

Experiments were performed in $25 \mathrm{~mL}$ sealed glass vials in a water bath at a constant temperature of $80{ }^{\circ} \mathrm{C}$. The composition of the base mixture is shown in Table 2.1. The specific compositions of other samples are mentioned in Table 2.2. In the case of solvent addition of ethanol and isopropanol, $20 \%$ of the solvent is added to the base mixture. All samples were aged at $80{ }^{\circ} \mathrm{C}$ for a period of 13 days. At every 12 hour interval, samples were cooled down and centrifuged for 20 minutes at $5000 \mathrm{rpm}$ to check for phase separation and samples were taken for GC-MS analysis.

Table 2.1: Model compounds and their concentrations in the base mixture.

\begin{tabular}{lll} 
Compound & Category & Concentration (wt\%) \\
\hline Acetic Acid & Carboxylic acids & 10 \\
Phenol & Aromatics & 25 \\
Guaiacol & Aromatics & 10 \\
Vanillin & Aromatics & 5 \\
Cyclopentanone & Ketone & 10 \\
Hydroxy Acetone & Ketone/ Cyclopentanones & 10 \\
Furan & Furans & 4 \\
Hydroxyl Aldehyde & Aldehydes & 1 \\
Water & Water & 25
\end{tabular}




\section{Table 2.2: Special conditions of the runs.}

Run No. All components in Table 1

\begin{tabular}{ll}
\hline 1 & All components in Table 1 except Acetic Acid \\
2 & All components in Table 1 except Sugar \\
3 & All components in Table 1 except Furan \\
4 & All components in Table 1 except Ketone \\
5 & All components in Table 1 except Aldehyde \\
6 & All components in Table 1 with $20 \%$ Isopropanol \\
7 & All components in Table 1 with $20 \%$ Ethanol
\end{tabular}

\subsubsection{Chemical composition of samples with aging time}

Gas chromatography - mass spectrometry

Samples were analyzed by gas chromatography-mass spectrometry (GC-MS) coupled with a flame ionization detector (FID). Mass spectrometry was used to identify the components and the flame ionization detector was used to determine their concentration. The GC-MS/FID was a Shimadzu GCMS-QP2010 plus, equipped with auto sampler/injector and a capillary column (RTX-1701) of $30 \mathrm{~m} \times 0.25 \mathrm{~mm}$ i.d. (film thickness: $0.25 \mu \mathrm{m}$, column flow rate: $0.75 \mathrm{~mL} / \mathrm{min}$, carrier gas: helium, maximum temperature: $280{ }^{\circ} \mathrm{C}$ ). Samples were mixed with an internal standard solution of 1-dodecanol at a 1:1 ratio, diluted with methanol at a 1:22 ratio and filtered using $0.2 \mu \mathrm{m}$ pore size TEFLON filters. Then, $1 \mu \mathrm{L}$ of sample was injected with a split ratio of 1:20 while the column was maintained at $45^{\circ} \mathrm{C}$ for 3 minutes before being heated, first to $220^{\circ} \mathrm{C}$ at a rate of $5{ }^{\circ} \mathrm{C} / \mathrm{min}$, then to $280{ }^{\circ} \mathrm{C}$ at a rate of $30{ }^{\circ} \mathrm{C} / \mathrm{min}$, where it was held for $3 \mathrm{~min}$. The identification of the peaks in the chromatogram was based on the comparison with spectra and retention times of known standards. Quantification of each group of compounds was done by manual integration of single ion chromatograms.

$\underline{\text { Water content }}$ 
Since the sample size was not large enough to measure the water content at each stage, the water content of each phase was measured after 10 days of aging using a Karl Fischer titrator.

\subsection{Results and discussion}

\subsubsection{Phase separation}

As shown in Table 2.3, phase separation occurred immediately after mixing the components with the samples without acids and without ketones. This can be due to lack of mutual solubility of phenols (which were in solid form) and other liquid components in the absence of acids and ketones. Other than those, the sample without aldehydes became phase separated after 4 days of aging at $80^{\circ} \mathrm{C}$, and the samples of the base case and the 'no furan' case do not display any phase separation after 13 days of aging, at which time the test was stopped.

Table 2.3: Time required for phase separation.

\begin{tabular}{|l|l|l|}
\hline Sample & $\begin{array}{l}\text { Time required for } \\
\text { phase separation at } \\
8{ }^{\circ} \mathrm{C}\end{array}$ & Remarks \\
\hline All components & $>13$ days & Clear good mixture at the end of 13 days of aging. \\
\hline $\begin{array}{l}\text { All components except } \\
\text { Acetic Acid }\end{array}$ & 0 & $\begin{array}{l}\text { Phase separated immediately after mixing. Top } \\
\text { phase mainly consists of water, phenol and linear } \\
\text { ketone. The proportion of each phase was not } \\
\text { increased with time. }\end{array}$ \\
\hline $\begin{array}{l}\text { All components except } \\
\text { Ketone }\end{array}$ & 0 & $\begin{array}{l}\text { Phase separated at the beginning. Top phase was } \\
\text { not enough for sampling. Only the bottom phase } \\
\text { was analysed. The proportions of phases were not } \\
\text { increased with time. }\end{array}$ \\
\hline $\begin{array}{l}\text { All components except } \\
\text { Furan }\end{array}$ & $>13$ days & $\begin{array}{l}\text { Clear good mixture at the end of 11 days of aging. } \\
\text { Aldehyde }\end{array}$ \\
\hline $\begin{array}{l}\text { All components except } \\
\text { consisted of water, phenol and linear ketone and }\end{array}$
\end{tabular}


Even though the water content was expected to increase during aging, it was reduced from its initial value of $25 \%$ in the case of the mixtures that did not undergo phase separation: the base case and the 'no furan' case. Table 2.4 shows that whenever phase separation occurred, the top phase had a much higher water content than the bottom phase.

Table 2.4: Water content of each phase after 10 days of aging at $80{ }^{\circ} \mathrm{C}$.

\begin{tabular}{|c|c|c|}
\hline & \multicolumn{2}{|c|}{ Water content $(\%)$} \\
\hline Sample & Top phase & Bottom phase \\
\hline All components & \multicolumn{2}{|l|}{16.96} \\
\hline $\begin{array}{l}\text { All components except } \\
\text { Acetic Acid }\end{array}$ & 79.2 & 12.7 \\
\hline $\begin{array}{l}\text { All components except } \\
\text { Ketone }\end{array}$ & 72.5 & 18.1 \\
\hline $\begin{array}{l}\text { All components except } \\
\text { Furan }\end{array}$ & \multicolumn{2}{|l|}{23.3} \\
\hline $\begin{array}{l}\text { All components except } \\
\text { Aldehyde }\end{array}$ & 70.6 & 18.7 \\
\hline
\end{tabular}

\subsubsection{Conversion of acetic acid}

Figure 2.1 shows the concentration of acetic acid is nearly constant during aging of the base case mixture. From that we can derive that acetic acid is not participating in the reaction in the base case. On the other hand, the addition of alcohol resulted in the gradual decrease of acetic acid concentration, and, hence, it can be concluded that acetic acid reacts with the alcohol that is added or with other components at the presence of alcohol. Ethanol converts more acetic acid than isopropanol does. 


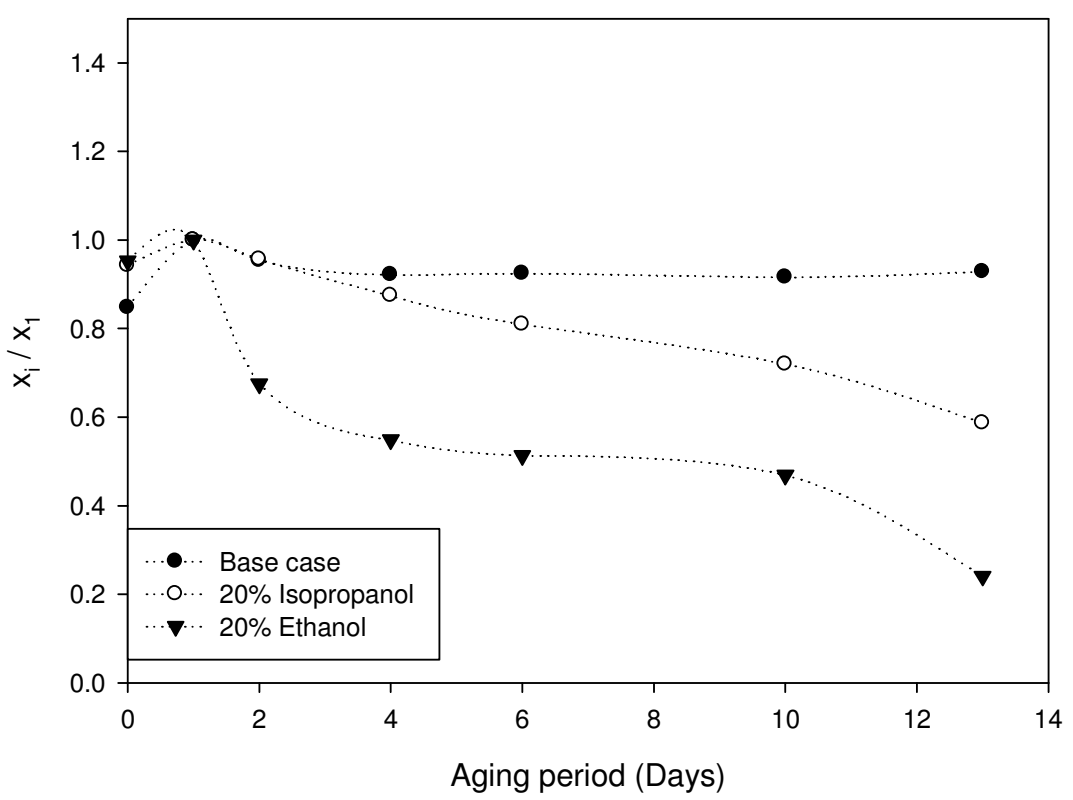

Figure 2.1: Conversion of acetic acid along the aging period of model compound with and without alcohol (mixture with all components)

$$
\begin{aligned}
& \mathrm{x}_{1}=\frac{(\text { Peak area of GC }- \text { FID for Acetic acid }) \text { at time } 1}{(\text { Peak area for internal standard }) \text { at time } 1} \\
& \mathrm{x}_{i}=\frac{(\text { Peak area of GC }- \text { FID for Acetic acid }) \text { at time } i}{(\text { Peak area for internal standard }) \text { at time } i}
\end{aligned}
$$

The conversion products of acetic acid were identified as 1-methylethyl ester and ethyl acetate in the case of isopropanol and ethanol respectively. As shown in Figure 2.2, the concentration of both esters increased continuously with aging time. Figure 2.1 and 2.2 clearly demonstrate how esterification of acetic acid with alcohol takes place during bio-oil aging at elevated temperatures. However, despite the experiments were started with no esters in the initial mixtures, an initial concentration of ester is measured in the analyzed samples, as shown in Figure 2.2. This may be the result of an esterification reaction that might have happened during GC-MS runs or during the sample sitting period before the analysis was conducted. 
Many other previous studies have identified a similar conversion of carboxylic acids into the respective esters at the presence of alcohol [7, 9, 14, 16]. Hu et al. [14] also stated that carboxylic acids are also efficient catalysts for the condensation reactions, such as the electrophilic substitution and aldol condensation reactions. However, $\mathrm{Hu}$ et al. [8] concluded that the molecular structure of acids in bio-oil significantly affect their acid-catalyzed conversion in methanol. They showed that an increase in molecular size significantly decreases the reactivity of acid, and acids with branched carbon chains have a lower conversion when compared to linear acids. Further, the study shows that aromatic acids are more difficult to esterify [8]. Therefore, a model compound study with different kinds of carboxylic acids would also be useful.

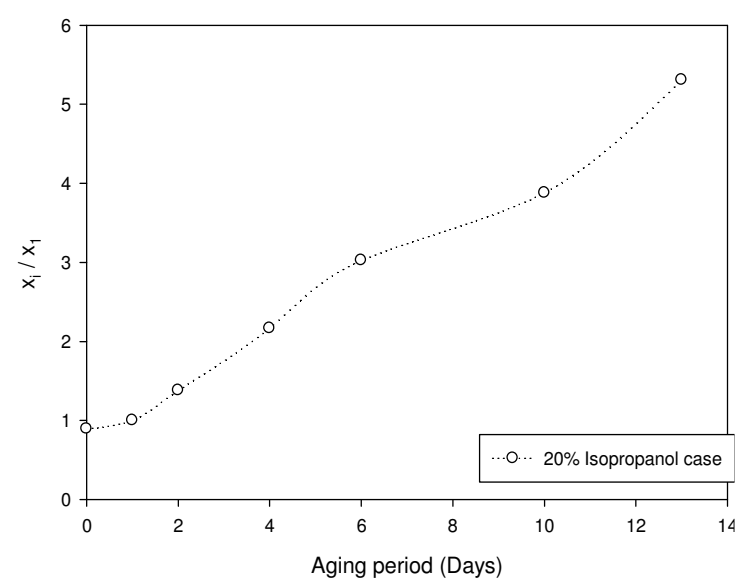

(a)

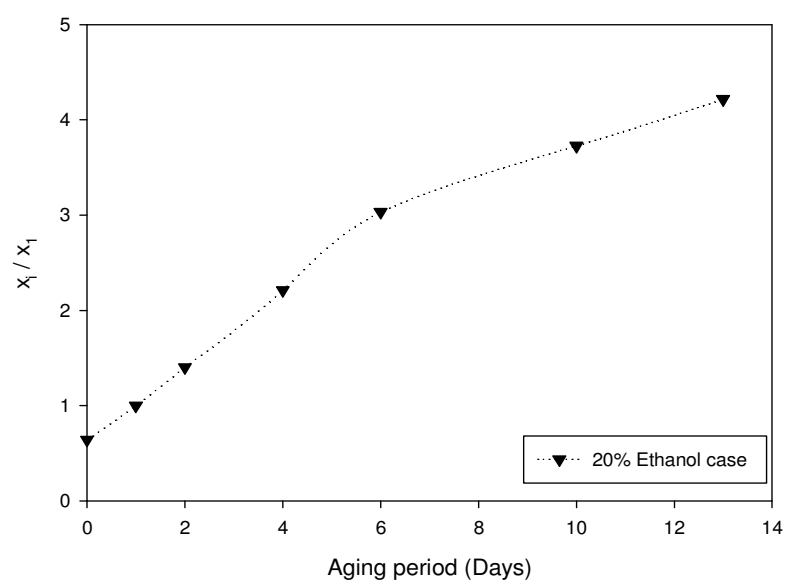

(b)

Figure 2.2: Evolution of esters along the aging period of model compound with alcohol, (a) acetic acid, 1-methylethyl ester, (b) ethyl acetate (mixture with all components)

$$
\begin{aligned}
& \mathrm{x}_{1}=\frac{(\text { Peak area of GC }- \text { FID for component } k) \text { at time } 1}{(\text { Peak area for internal standard }) \text { at time } 1} \\
& \mathrm{x}_{i}=\frac{(\text { Peak area of } G C-\text { FID for component } k) \text { at time } i}{(\text { Peak area for internal standard }) \text { at time } i}
\end{aligned}
$$




\subsubsection{Conversion of ketones and aldehydes}

Most of the research highlights that carbonyl components are the most reactive groups and are particularly important in bio-oil upgrading [9, 21]. In this study, 1-hydroxy-2-propanone and cyclopentanone were used as two ketones and 2-propenal (or acrolein) as the aldehyde in the model compounds mixture.

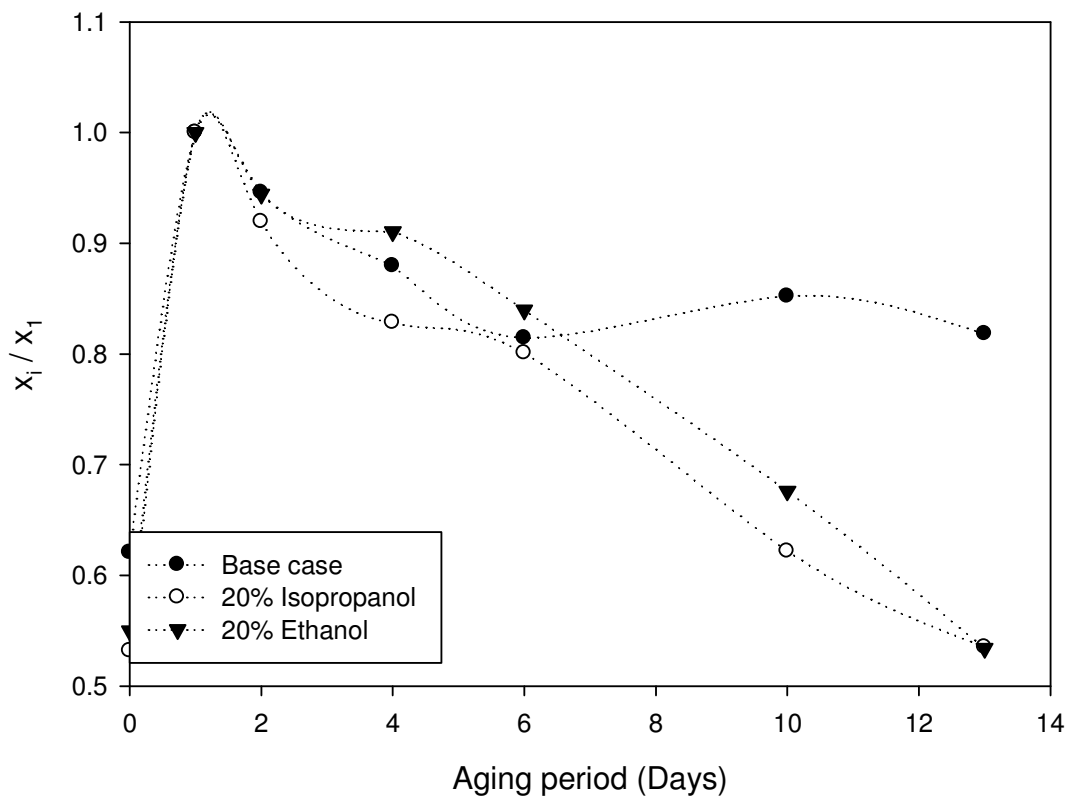

Figure 2.3: Evolution of 1-hydroxy-2-Propanone along the aging period of model compound with and without alcohol (mixture with all components)

$$
\begin{aligned}
\mathrm{x}_{1} & =\frac{(\text { Peak area of GC }- \text { FID for } 1-\text { hydroxy }-2-\text { Propanone }) \text { at time } 1}{(\text { Peak area for internal standard }) \text { at time } 1} \\
\mathrm{x}_{i} & =\frac{(\text { Peak area of GC }- \text { FID for } 1-\text { hydroxy }-2-\text { Propanone }) \text { at time } i}{(\text { Peak area for internal standard }) \text { at time } i}
\end{aligned}
$$

Figure 2.3 shows that the concentration of 1-hydroxy-2-propanone first increases sharply and then decreases gradually in all the three cases. However, in the base case, the decline flattens out after 6 days of aging, whereas the concentration continues to decline in media containing alcohols. Some of the previous studies also confirm the decline of the ketones during of bio-oil aging $[22,23]$. 
Ketones and aldehydes are known to undergo condensation reactions either as two ketones, two aldehydes or a combination of a ketone and an aldehyde. This process is called aldol condensation [24]. However, in this study, these condensation reaction products were not detected through GC-MS. They can either be in the heavy fraction or may have not been stable and converted into other products. Snell et al. have concluded that weak acid groups play a crucial role in the condensation reactions, particularly with the cross condensation of aldehydes and ketones [24].

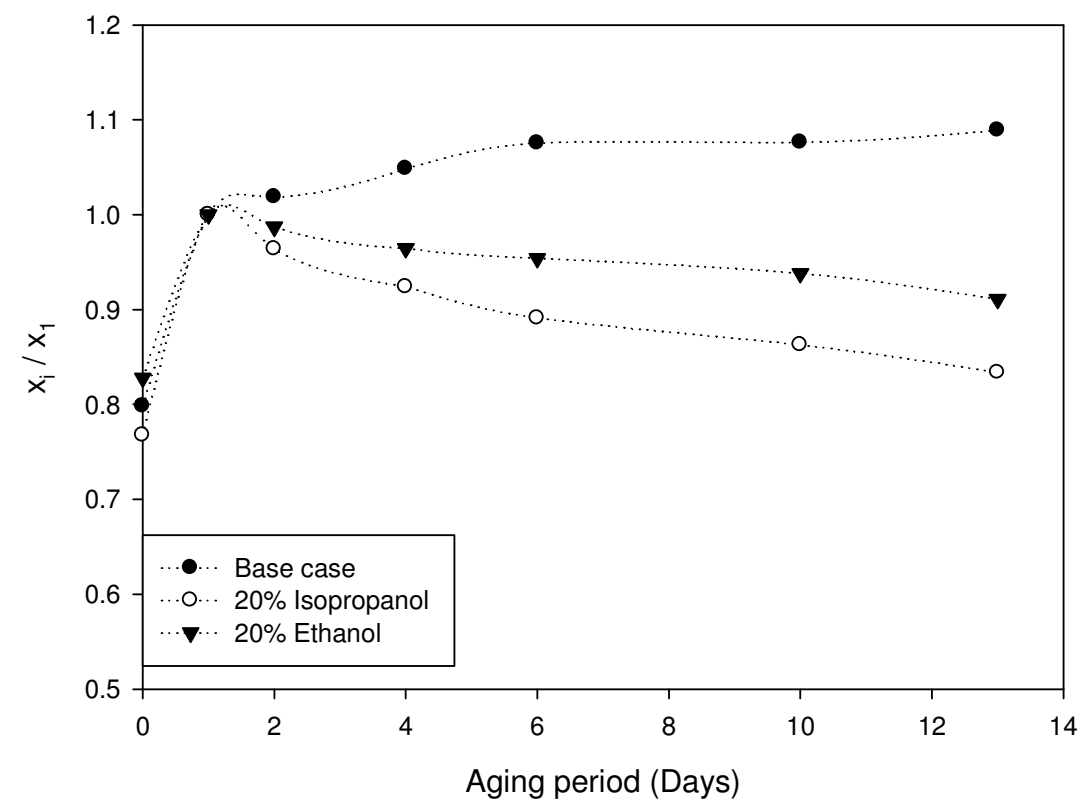

Figure 2.4: Evolution of cyclopentanone along the aging period of model compound with and without alcohol (mixture with all components)

$$
\begin{aligned}
& \mathrm{x}_{0}=\frac{(\text { Peak area of GC }- \text { FID for Cyclopentanone }) \text { at time } 0}{(\text { Peak area for internal standard }) \text { at time } 0} \\
& \mathrm{x}_{i}=\frac{(\text { Peak area of } G C-F I D \text { for Cyclopentanone }) \text { at time } i}{(\text { Peak area for internal standard }) \text { at time } i}
\end{aligned}
$$

Figure 2.4 shows that the concentration of cyclopentanone increases sharply at first and then increases gradually without additive; with alcohol additives, the concentration of cyclopentanone increases sharply at first and then decreases gradually with time. Although Figure 2.5 suggests that some cyclopentanone is converted to 1,1-dimethoxycyclopentane during aging, the lack of a 
direct correspondence between the results of Figures 2.4 and 2.5 indicates that other compounds must be involved.

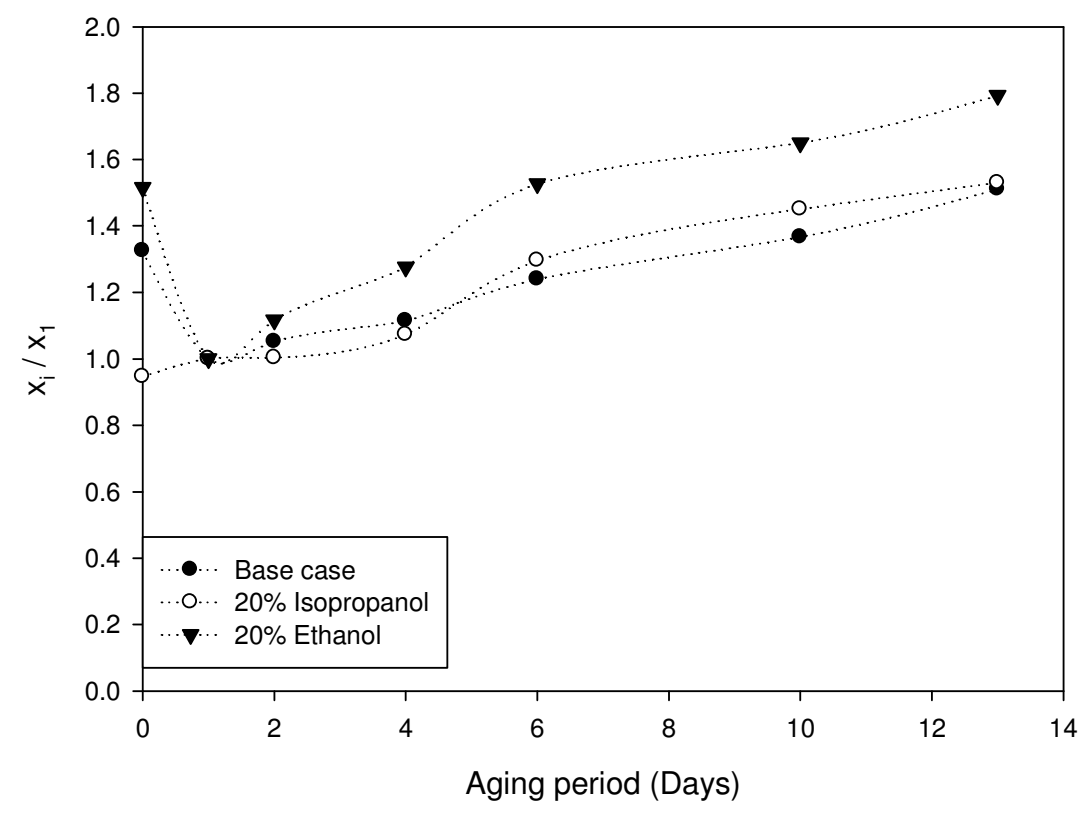

Figure 2.5: Evolution of 1,1-dimethoxycyclopentane along the aging period of model compound with and without alcohol (mixture with all components)

$$
\begin{aligned}
& \mathrm{x}_{0}=\frac{(\text { Peak area of } G C-\text { FID for } 1,1-\text { dimethoxycyclopentane }) \text { at time } 0}{(\text { Peak area for internal standard }) \text { at time } 0} \\
& \mathrm{x}_{i}=\frac{(\text { Peak area of } G C-\text { FID for } 1,1-\text { dimethoxycyclopentane }) \text { at time } i}{(\text { Peak area for internal standard }) \text { at time } i}
\end{aligned}
$$

2-propenal was not detected in any of the samples. However, acrolein dimethylacetal was detected in all the samples only at 24 hours of aging and not later on. Most likely, acrolein dimethylacetal was then decomposed into other components. Figure 2.6 shows the concentration of 2,2-dimethoxy-propane, which could be a decomposed product from acrolein dimethylacetal. $\mathrm{Hu}$ et al. also stated that acetalization of simple aldehydes such as formaldehyde and acetaldehyde took place as soon as the bio-oil was mixed with methanol at room temperature [9]. 
They also found that small acetals are not stable at high temperature and would be decomposed to aldehydes and other ethers and alcohols.

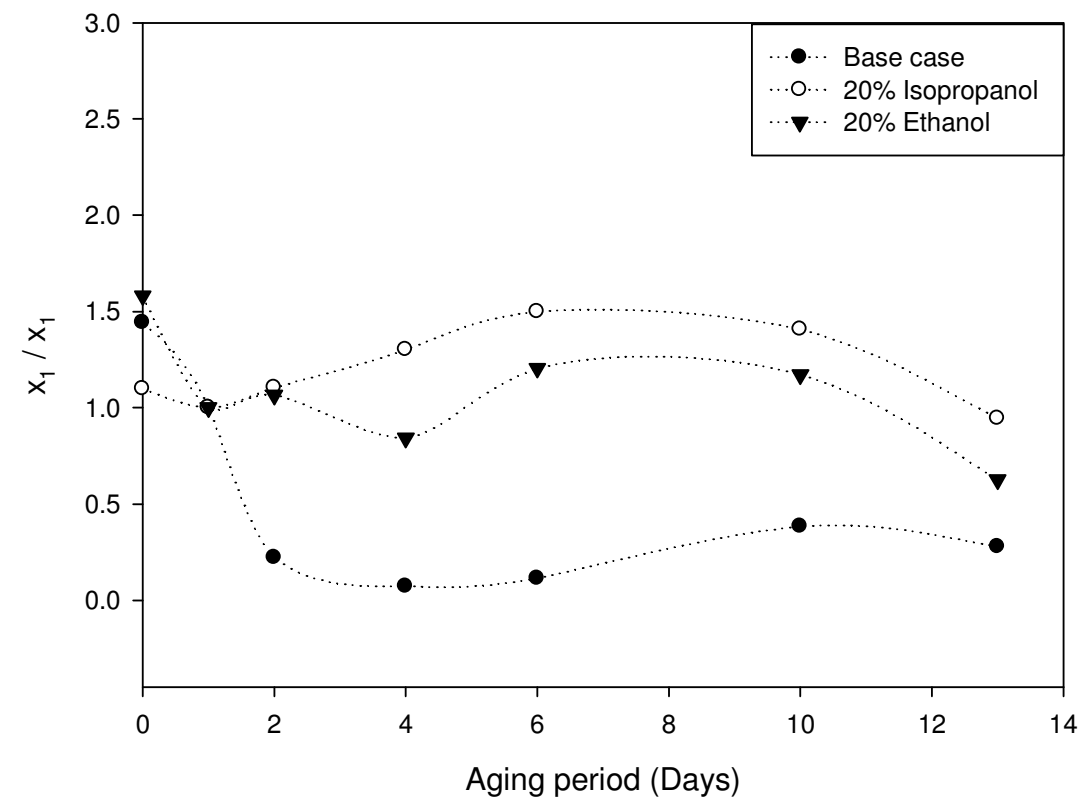

Figure 2.6: Evolution of 2,2-dimethoxy-propane along the aging period of model compound with and without alcohol (mixture with all components)

$$
\begin{aligned}
& \mathrm{x}_{1}=\frac{(\text { Peak area of GC }- \text { FID for } 2,2-\text { dimethoxy }- \text { propane }) \text { at time } 1}{(\text { Peak area for internal standard }) \text { at time } 1} \\
& \mathrm{x}_{i}=\frac{(\text { Peak area of } G C-\text { FID for } 2,2-\text { dimethoxy }- \text { propane }) \text { at time } i}{(\text { Peak area for internal standard }) \text { at time } i}
\end{aligned}
$$

Li et al. also noted a very similar type of reaction during aging of bio-oil. The results show that the light organic acids and aldehydes simultaneously convert into esters and acetals at elevated temperatures and longer reaction period [7].

However, both in Figure 2.5 and 2.6, the chemical compositions of 1,1-dimethoxycyclopentane and 2,2-dimethoxy-propane at time 0 was not zero. This might be the result of reactions occurred before the samples were analyzed by the GC and/or during the analysis. If that is the case, sharp reduction of components might be a results of either decomposed or vaporized from the rest of the samples during sample preparation for GC runs and in other steps. 


\subsubsection{Conversion of Phenols}

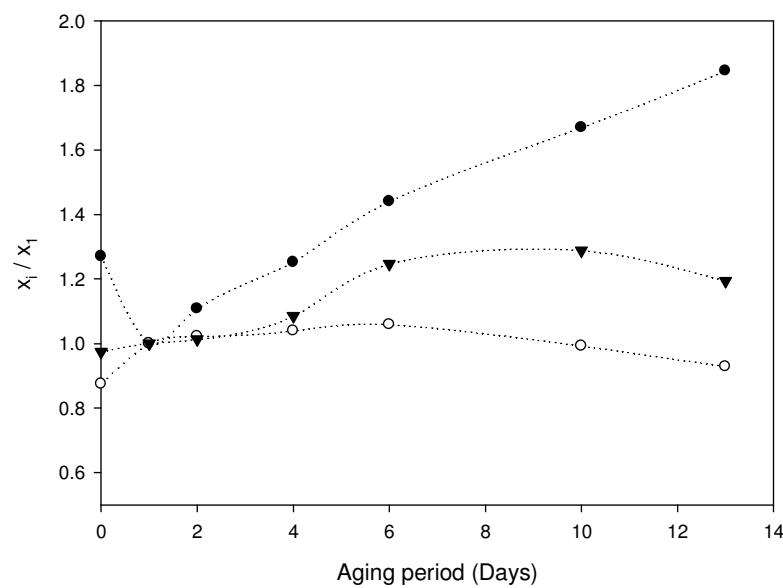

(a)

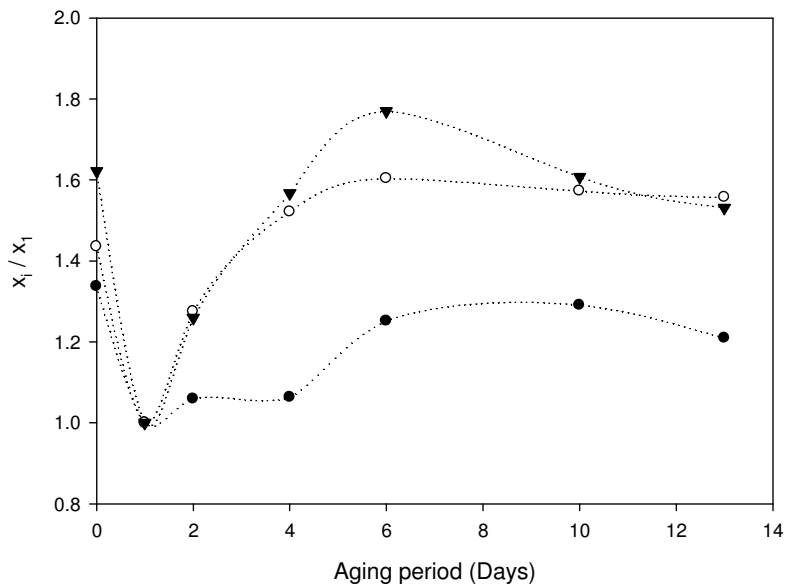

(c)

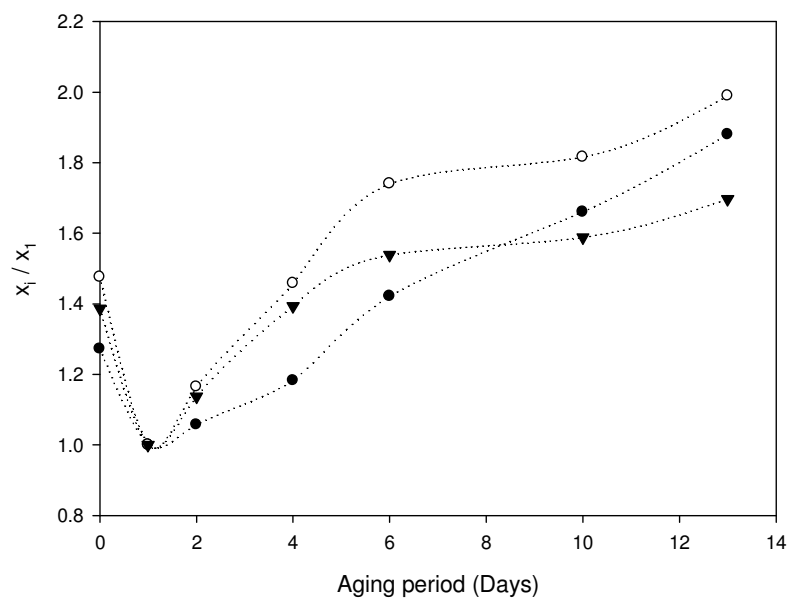

(b)
- Base case

- Base case $+20 \%$ Isopropanol

- Base case+ $20 \%$ Ethanol

Figure 2.7: Evolution of phenolics along the aging period of model compound with and without alcohol; (a) phenol, (b) phenol, 2-methoxy-, (c) vanillin (mixture with all components).

$$
\begin{aligned}
& \mathrm{x}_{1}=\frac{(\text { Peak area of GC }- \text { FID for component } k) \text { at time } 1}{(\text { Peak area for internal standard }) \text { at time } 1} \\
& \mathrm{x}_{i}=\frac{(\text { Peak area of GC }- \text { FID for component } k) \text { at time } i}{(\text { Peak area for internal standard }) \text { at time } i}
\end{aligned}
$$


Figure 2.7 shows that there is a sharp initial drop in the concentration of all three phenolics compounds when alcohol is not added and only of guaiacol and vanillin when either of the alcohols is added. The concentrations gradually increase afterwards. The concentration of vanillin started declining after 6 days, whereas guaiacol and phenol continued to increase in concentration. However, in previous researches, Kim et al. found that phenolics gradually decreased with prolonged storage of bio-oil, whereas the yield of pyrolitic lignin extracted from bio-oil increased with storage duration [22]. Oasmaa et al. also confirm the same results [23].

\subsubsection{What happened to furans?}

Furan was also not detected in any of the samples and it can be possible that furan had reacted very fast, possibly soon after mixing with other components. Furan derivatives are not consistently detected in samples over time. However, some of the products derived from furan such as 2-hexyl furan; trans-2-(2-Pentenyl)furan; 2,5-dihydro-2,2,4-trimethyl furan were detected in some of the samples. Therefore, furan derivatives were either decomposed or reacted to form higher molecular weight components that were not detected by GC-MS. Similarly, Hu et al. found that furan compounds which contain carbonyl groups also go through acetalization and etherification reactions and found that most of these acetals are not stable at elevated temperatures [9].

\subsubsection{Is there an impact from operating conditions of the GC-MS towards results?}

Some of the identified resulting components such as 1,1-dimethoxycyclopentane and 2,2dimethoxy-propane contains methyl or methoxy groups even when an alcohol is not added to the samples as a stabilizer. Further, these components were appeared before any aging took place (Figure 2.5 and Figure 2.6). It might be that these are an artefact introduced by the analytical procedure, though reactions at the high GC temperatures with the methanol that was used to dilute the sample in GC-MS analysis or with the 1-Dodecanol that was used as internal standard.

Therefore, two similar sets of experiments were performed using two different conditioning procedures of the samples prepared for the GC-MS. One is the normal procedure using 1- 
Dodecanol as internal standard and methanol as solvent, as explained in section 2.2.3. The second set was run with dodecane as internal standard and acetone as solvent.

The esterification reactions were not affected by the GC-MS conditioning procedure since there was no significant difference in the acid concentration between the two conditioning procedures. However, it was noted that other components such as 1,1-dimethoxycyclopentane and 2,2dimethoxy-propane were present only when the regular conditioning procedure had been used. Light components such as aldehydes and furans or their derivatives were not identified with conditioning procedure. Therefore, it can be concluded that, with the regular sample conditioning procedure for the GC-MS, ketones react with the methanol solvent during sample preparation or within the GC.

\subsection{Conclusions}

Even though acids and ketones are some of the more reactive and detrimental component groups in bio-oil, the presence of those components helps improve the mutual solubility of the mixture, preventing or retarding phase separation.

Carboxylic acids are converted to esters in the presence of alcohol and these esters seem to be very stable at elevated temperatures for prolonged periods of time. On the other hand, most of the derivatives from linear ketones and aldehydes (mainly acetals) are not stable at experimental conditions. They either decomposed into other products or reacted to form higher molecular weight components that were not detected by GC-MS. The same results were observed with furan and furan derivatives. Furan and aldehydes were the fastest reactive compounds amongst these model components. There is a sharp initial drop of the concentration of all three phenolics compounds when alcohol is not added and only of guaiacol and vanillin when either of the alcohols is added. The concentrations gradually increase afterwards. The concentration of vanillin started declining after 6 days, whereas guaiacol and phenol continued to increase in concentration. 


\subsection{References}

[1] Diebold, J. P. (2000). A review of the chemical and physical mechanisms of the storage stability of fast pyrolysis bio-oils. NREL/SR-570-27613. Colorado, National Renewable Energy Laboratory.

[2] Diebold, J. P. and Czernik, S. (1997). Additives to lower and stabilize the viscosity of pyrolysis oil during storage. Energy\& Fuels 1997, 11, 1081-1091

[3] Oasmaa, A. and Kuoppala, E. (2003). Fast pyrolysis of forestry residue. 3. Storage stability of liquid fuel. Energy \& Fuels 2003, 17, 1075-1084

[4] Czernik, S., Johnson, D. K., Black, S. (1994). Stability of wood fast pyrolysis oil. Biomass and Bioenergy, 7(1-6), 187- 192.

[5] Oasmaa, A. and Czernik, S. (1999). Fuel oil quality of biomass pyrolysis oils- state of the art for the end users. Energy \& Fuels 1999, 13, 914-921.

[6] Demirbas, A. (2007). The influence of temperature on the yield of compounds existing in bio-oils obtained from biomass samples via pyrolysis. Fuel Processing Technology, 88(2007), 591-597.

[7] Li., X., Gunawan, R., Lievens, C., Wang, Y., Mourant, D., Wang, S., Wu, H., GarciaPerez, M. and Li, C. Z. (2011). Simultaneous catalytic esterification of carboxylic acids and acetalisation of aldehydes in fast pyrolysis bio-oil from mallee biomass. Fuel, 90(2011), 25302537.

[8] Hu, X., Mourant, D., Wang, Y., Wu, L., Chaiwat, W. Gunawan, R., Gholizadeh, M., Lievens, C., Garcia-Perez, M., Li, C. Z. (2013). Acid-catalysed treatment of the mallee leaf biooil with methanol: Effects of molecular structure of carboxylic acids and esters on their conversion. Fuel Processing Technology, 106(2013), 569-576.

[9] Hu, X., Gunawan, R., Mourant, D., Lievens, C., Li, X., Zhang, S. and Chaiwat, W. (2012). Acid-catalysed reaction between methanol and bio-oil from fast pyrolysis of mallee bark. Fuel, 97(2012), 512-522. 
[10] Moens, L., Black, S. K., Myers, M. D. and Czernik, S. (2009). Study of the neutralization and stabilization of a mixed hardwood bio-oil. Energy \& Fuels 2009, 23, 2695-2699.

[11] Wang, J. J., Chang, J., Fan, J. (2010). Upgrading of bio-oil by catalytic esterification and determination of acid number for evaluating esterification degree. Energy \& Fuels2010, 24, 3251-3255.

[12] Song, M., Zhong, Z., and Dai, J. (2010). Different solid acid catalysts influence on properties and chemical composition change of upgrading bio-oil. Journal of Analytical and Applied Pyrolysis, 89(2010), 166-170.

[13] Xiong, W. M., Zhu, M. Z., Deng, Z., Fu, Y., and guo, Q. X., (2009). Esterification of organic acid in bio-oil using acidic ionic liquid catalysts. Energy \& fuels, 23(2009), 2278-2283.

[14] Hu, X., Wang, Y., Mourant, D., Gunawan, R., Lievens, C., Chaiwat, W., Gholizadeh, M., Wu, L., Li, X. and Li, C. Z. (2012). Polymerization on heating up of bio-oil: A model compound study. AIChE Journal, O0(0), 1-10. DOI: 10.1002/aic.13857.

[15] Wang, S., Guo, Z., Cai, Q. and Guo, L. (2012). Catalytic conversion of carboxylic acids in bio-oil for liquid hydrocarbons production. Biomass and bioenergy, 45 (2012), 138-143.

[16] Lohitharn, N., and Shanks, B. H. (2009). Upgrading of bio-oil: Effect of light aldehydes on acetic acid removal via esterification. Catalysis Communications, 11 (2009), 96-99.

[17] Gu, Y., Xu, G., Guo, Z., and Wang, S. (2012). Esterification research on a bio-oil model compounds system with an optimal solid acid catalyst. Advanced Materials Research, 383-390 (2012), 1144-1149.

[18] Zhang, Z., Sui, S., Tan, S., Wang, Q., and Pittman Jr. C. U. (2013). Catalytic conversion of bio-oil to oxygen containing fuels by simultaneous reactions with 1-butanol and 1-octene over solid acids: Model compound studies and reaction pathways. Bioresource Technology, http://dx.doi.org/10.1016/j.biortech.2012.11.060. 
[19] Yang, X., Chatterjee, S., Zhang, Z., Zhu, X., and Pittman, Jr. C. U. (2010). Reactions of phenol, water, acetic acid, methanol, and 2-hydroxymethylfuran with olefin and models for biooil upgrading. Industrial and Engineering Chemistry Research, 49 (2010).2003- 2013.

[20] Gunawan, R., Li, X., Larcher, A., Hu, X., Mourant, D., Chaiwat, W. and Wu, H. (2012). Hydrolysis and glycosidation of sugars during the esterification of fast pyrolysis, Fuel, 95(2012), 146-151.

[21] Lievens, C., Mourant, D., He, M., Gunawan, R., Li, X., and Li, C. Z. (2011). An FT-IR spectroscopic study of carbonyl functionalities in bio-oils. Fuel, 90 (11), 3417-3423.

[22] Kim, T. S., Kim, J. Y., Kim, K. H., Lee, S. and Choi, D. (2012). The effect of storage duration on bio-oil properties. Journal of Analytical and Applied Pyrolysis, 95(2012), 118-125.

[23] Oasmaa, A., Korhonen, J. and Kuoppala, E. (2011). An approach for stability measurement of wood-based fast pyrolysis bio-oil. Energy \& Fuels 2011, 25, 3307-3313.

[24] Snell, R. W., Combs, E., and Shanks, B. H. (2010). Aldol condensations using bio-oil model compounds: The role of acid-base bi-functionality. Topics in Catalysis. 53(2010), 12481253. 


\section{Chapter 3}

\section{Change in physical properties and chemical composition during aging of dry birch bark bio-oil from fractional condensation}

\subsection{Introduction}

Pyrolysis of biomass to the liquid biofuel called bio-oil is one of the most promising technologies for the conversion of biomass to biofuel. At room temperature, bio-oil is often, initially, a single phase, dark, viscous liquid that contains more than 300 chemical components [1- 4]. However, when compared to conventional liquid fuels, bio-oil has several undesired properties such as high viscosity, high acidity, high molecular weight, instability and phase separation upon aging, which means that properties, such as viscosity, change with storage time and temperature [1-4]. Further, the high oxygen (typically 45-50 wt\%) and water contents (typically 15-30 wt\%) of pyrolysis oil result in a lower energy density than conventional fuel oils $[5,6]$. Previous studies have characterized the aging of bio-oil by monitoring changes in absolute viscosity [2-4], water content [7], molecular weight [1-4, 8], or carbonyl content [9].

The quality and stability indicators are directly related to the chemical composition of bio-oil, which is a poorly defined mixture of acids, alcohols, aldehydes, esters, ketones, sugars, phenols, guaiacols, syringols, furans, and multifunctional compounds [10]. Therefore, the quality or the stability of bio-oil can be improved by modifying its chemical composition. This can be achieved by upgrading the feedstock by torrefaction [11, 12] or pre-treating the biomass [13], by controlling the pyrolysis conditions [14 - 18], by using only a selective part of biomass with specific qualities such as cellulose, hemicellulose or lignin [14 -15], or by downstream fractionating of bio-oil through methods such as molecular distillation [19]. Azeez et al. found that the acidity of bio-oil can be reduced through careful control of pyrolysis condensation temperature [19]. Guo shows that molecular distillation can be used to reduce the water content and acidity of bio-oil; the refined bio-oil yield is then about $40 \%$ of the total oil and its heating value is increased by nearly $50 \%$ [20]. Westerhof et al. showed that the water content of 
pyrolysis oil from fast pyrolysis of biomass can be regulated by changing the condenser temperature, but removing water is always accompanied by the loss of organic vapors in the condenser and hence a reduction in bio-oil yield [16]. Dong et al. studied the effect of pyrolysis temperature on the concentration of each group of components in pyrolysis bio-oil [14]; they found that acetic acid is mainly derived from deacetylation of the hemicellulose and the fragmentation of holocellulose and low temperature fast pyrolysis was more favorable to acetic acid. Demirbas found that acetic acid comes from all three components of biomass (cellulose, hemicellulose and lignin) whereas furans form by dehydration of hemicellulose units [15].

The concentration method, i.e. the removal of light fractions from bio-oil and their replacement by an alcohol, increases the oil stability [21]. Fractional condensation has been used to lower the temperature of pyrolytic vapors in stages, to obtain bio-oil cuts of different compositions [19, 22 - 25]. Chen et al. studied the effect of fractional condensation on bio-oil products using four condensers connected in series with an electrostatic precipitator (ESP) [26]. They noticed that the bio-oil condensed in the lower temperature condensers has a lower water content, a higher $\mathrm{pH}$, a higher heating value, and a higher kinetic viscosity compared to the bio-oil collected from the higher temperature condenser. Westerhof et al. showed that a two condenser system can be used to remove the majority of water and light compounds, especially the carboxylic acids from the bio-oil [22]. Guo stated that the removal of the light fraction, which has high contents of water and acids, has the dual advantage of increasing the combustibility and decreasing the corrosiveness of the other fractions of oil [27]. Pollard et al. also showed that fractional condensation can be used to control the water content as well as the acid content of the bio-oil produced [23]. Tzanetakis et al. used fractional condensation to obtain a homogeneous single phase liquid bio-oil that remained a homogeneous single phase liquid after 7 months of storage at room temperature [24]. Tumbalam Gooty [25] stated that the bio-oil recovered in the first and second condensers of a three condenser fractionation have found to contain less than $1 \mathrm{wt} \%$ water and that this dry bio-oil fraction has a heating value slightly better than the ethanol. Therefore, the author concluded that the fractional condensation is a promising process to produce high quality fuels with higher HHV. However, a detailed understanding of the evolution of chemical components during aging for the dry bio-oils obtained with fractional condensation is lacking in the literature base. 
Therefore, the purpose of the study is to analyse the changes in chemical composition of each group of components of different cuts and different combinations of cuts from a fractional condensation train with three condensers.

\subsection{Materials and methods}

\section{Pyrolysis unit and condenser unit of bio-oil}

Birch bark particles were pyrolyzed in a $1 \mathrm{~kg} / \mathrm{h}$ fluidized bed continuous fast pyrolysis plant unit located at the Institute of Chemical and Fuels and Alternative Resources (ICFAR), London, Ontario, Canada. Nitrogen was used as fluidization gas. For these experiments, the bed temperature was maintained at $550{ }^{\circ} \mathrm{C}$. A detailed description of the bubbling bed reactor can be found in Tumbalam Gooty's work [25]. The schematic diagram of the condenser train is shown in Figure 3.1 [25].

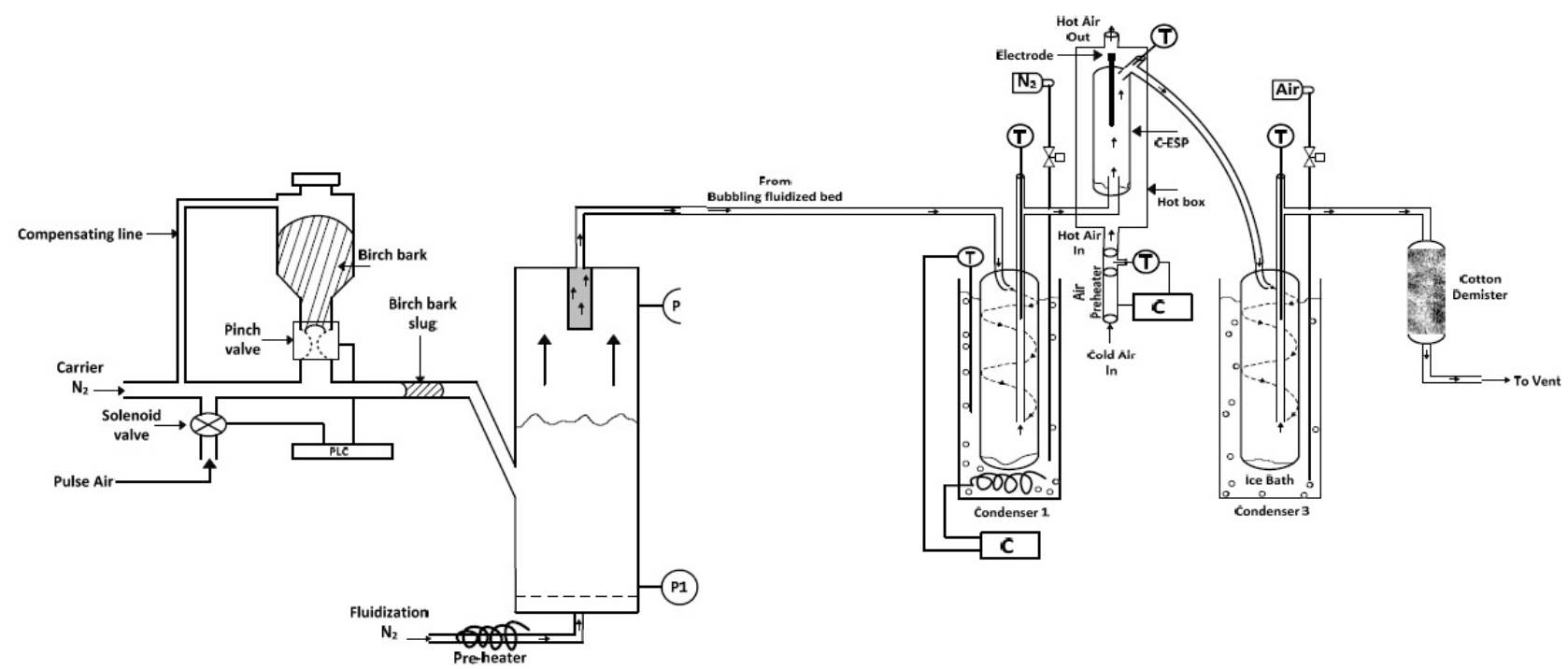

Figure 3.1: The schematic diagram of the fluidized bed reactor and the condenser train [25]

The vapor from the pyrolysis plant was collected in three condensers in series. Condenser 1 was maintained at $80{ }^{\circ} \mathrm{C}$, whereas the temperature of condenser 2 was varied from 50 to $70{ }^{\circ} \mathrm{C}$ and 
condenser 3 was in an ice bath. Condenser 2 incorporates an electrostatic precipitator (ESP) to recover the persistent bio-oil mist.

\section{Accelerated aging of bio-oil fractions and combinations}

Different fractions of bio-oil from birch bark, and their combinations, were dissolved and mixed in $25 \mathrm{wt} \%$ isopropanol and aged for different aging periods in a constant temperature water bath at $80{ }^{\circ} \mathrm{C}$. The samples were stored in sealed $30 \mathrm{~mL}$ glass vials in the vertical position and their weights were measured before and after aging. The aged bio-oil samples were analysed by GCMS/FID, and their heating value (HHV), water content and $\mathrm{pH}$ were measured.

Gas chromatography - mass spectrometry

The samples of each fractions and combinations were analysed by gas chromatography-mass spectrometry (GC-MS) coupled with a flame ionization detector (FID). Mass spectrometry was used to identify the components and the flame ionization detector was used to determine their concentration. The GC-MS/FID was a Shimadzu GCMS-QP2010 plus, equipped with auto sampler/injector and a capillary column (RTX-1701) of $30 \mathrm{~m}$ x $0.25 \mathrm{~mm}$ i.d. (film thickness: 0.25 $\mu \mathrm{m}$, column flow rate: $0.75 \mathrm{~mL} / \mathrm{min}$, carrier gas: helium, maximum temperature: $280{ }^{\circ} \mathrm{C}$ ). Samples were mixed with internal standard solution 1-dodecanol at 1:1 ratio and diluted with methanol at 1:22 ratio and filtered using $0.2 \mu \mathrm{m}$ pore size TEFLON filters. Then, $1 \mu \mathrm{L}$ of sample was injected with a split ratio of 1:20 while the column was maintained at $45{ }^{\circ} \mathrm{C}$ for 3 minutes before being heated to $220{ }^{\circ} \mathrm{C}$ at a rate of $5{ }^{\circ} \mathrm{C} / \mathrm{min}$, then the column was heated to $280{ }^{\circ} \mathrm{C}$ at a rate of $30^{\circ} \mathrm{C} / \mathrm{min}$, and held for $3 \mathrm{~min}$. The identification of the peaks in the chromatogram was based on the comparison with standard spectra and/or on the retention time of known standards. Quantification of each group of compounds was performed by manual integration of single ion chromatograms.

\section{$\underline{\text { Water content, higher heating value (HHV) and } \mathrm{pH}}$}

The water content of each phase is measured using the Mettler Toledo volumetric Karl Fischer titrator using AquaStar CombiSolventKeto as the titrant. The HHV for top and bottom phases and each aged sample was measured with the bomb calorimeter (IKA C200). The pH value for each fraction was also measured. 


\subsection{Results and discussion}

\subsubsection{Properties of different fractions of bio-oil derived from birch bark}

Given its high water content, the bio-oil fraction that is collected in condenser 3 is called the 'aqueous cut' and the fraction that is collected in condenser 2 is called the 'second condenser cut' while the fraction that is collected in condenser 1 is called the 'solid cut', since it is typically a solid material at room temperature which cannot be dissolved in alcohol. Therefore, it is recommended that the solid cut should be recycled in the pyrolysis process. The 'second condenser cut' is a viscous oil at room temperature. Therefore, in order to make a liquid fuel and to reduce the viscosity, it is dissolved in isopropanol. As illustrated in Chapter 1, isopropanol has been identified as the best alcohol amongst those tested that can be used to avoid the phase separation of bio-oil during aging. For example, the viscosity of oil mixed with $20 \%$ isopropanol was $182 \mathrm{cP}$ at $50{ }^{\circ} \mathrm{C}$, whereas the viscosity was $110 \mathrm{cP}$ when the oil was mixed with $25 \%$ isopropanol at the same temperature. Each fraction and combinations were mixed with $25 \mathrm{wt} \%$ isopropanol in each step of analysis.

As shown in Figure 3.2, the aqueous cut contains more than $60 \mathrm{wt} \%$ of water, and has a very high acidity and a very low HHV. On the other hand, the solid cut, the "solid material" recovered from the first condenser, has less than $2 \%$ of water, and a very high HHV for a bio-oil. However, as it was stated earlier, it cannot be dissolved in alcohol and cannot make a liquid fuel. The most interesting fraction was the 'second condenser cut', which represents more than $50 \%$ of the whole bio-oil. Compared to the whole bio-oil, the 'second condenser cut' has a very low water content (about 5\%) and acidity, and a high HHV. 


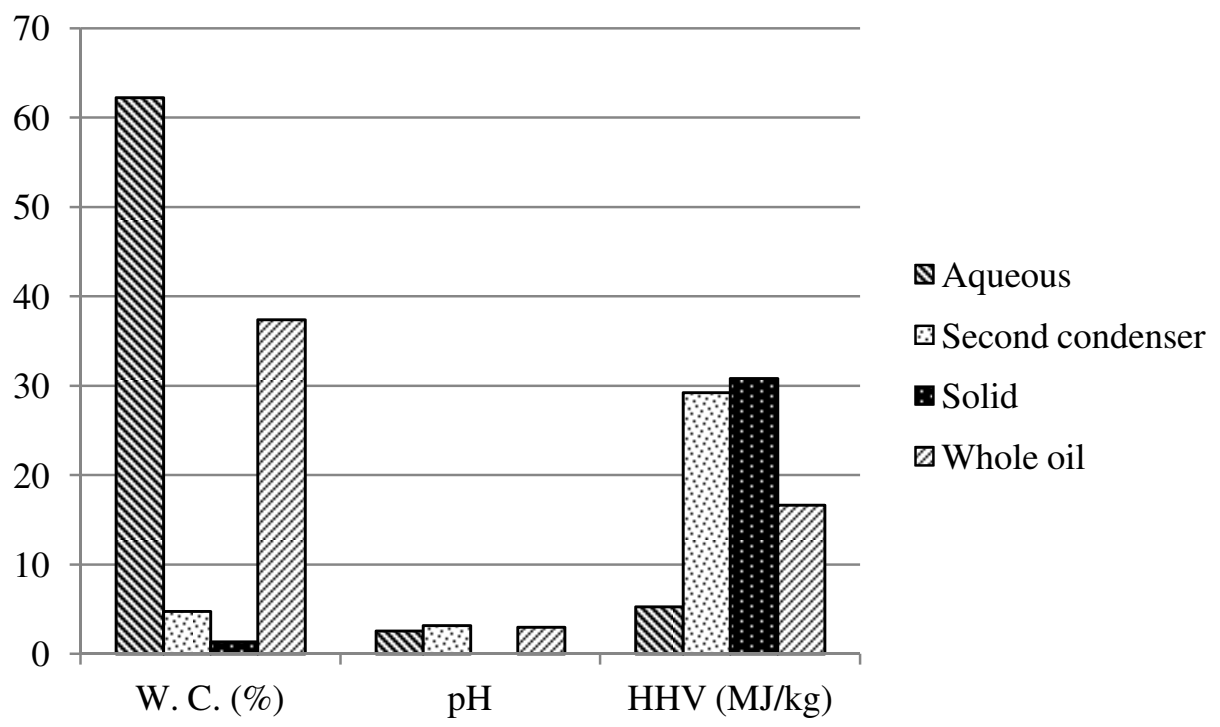

Figure 3.2: Water content, $\mathrm{pH}$ and HHV of different fractions of bio-oil derived from birch bark (with the condenser 2 maintained at $70{ }^{\circ} \mathrm{C}$ ).

\subsubsection{Effect of the temperature of the second condenser}

As mentioned earlier, the temperatures of condenser 1 and 3 were kept constant and the temperature of the condenser 2 was varied between 50 and $70{ }^{\circ} \mathrm{C}$. Figure 3.3 shows the values of water content, $\mathrm{pH}$ and $\mathrm{HHV}$ for different temperatures of condenser 2. The results show that reducing the temperature of the condenser 2 from 70 to $50{ }^{\circ} \mathrm{C}$ would increase the water content and slightly lower the HHV. Consequently, condenser 2 was maintained at a temperature of 70 ${ }^{\circ} \mathrm{C}$ for the rest of this study. 


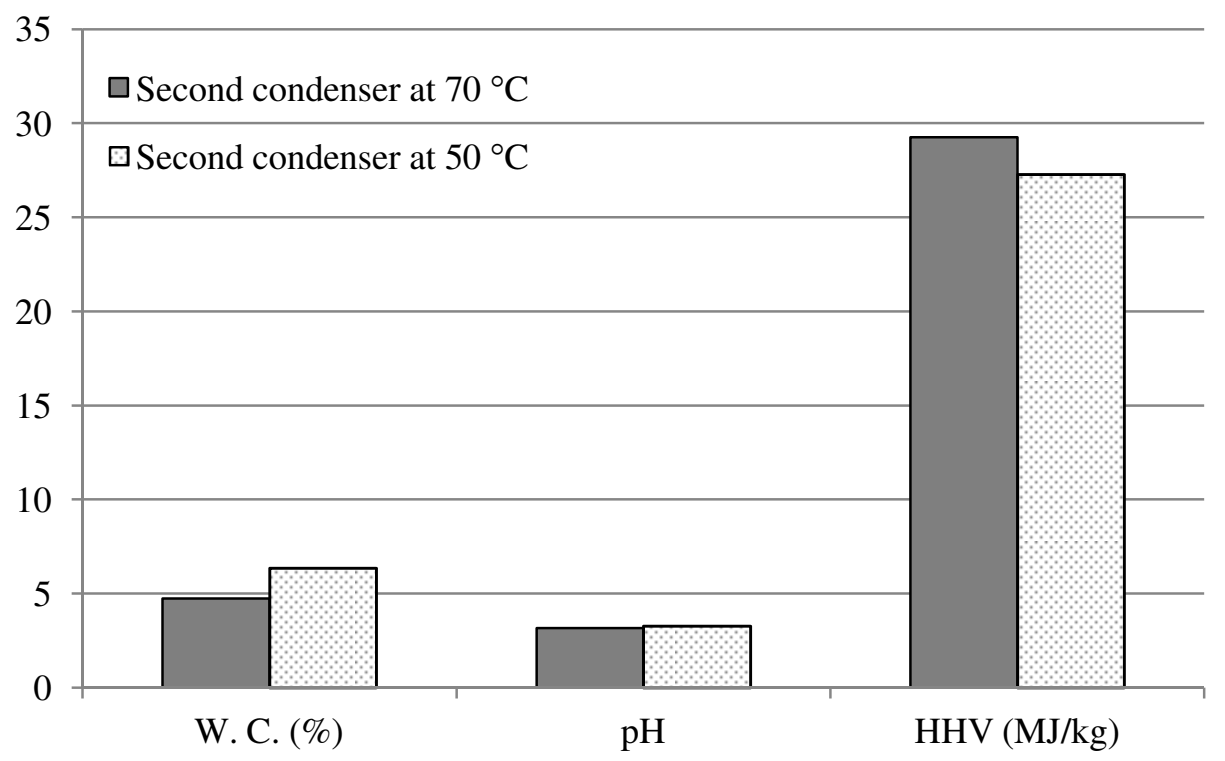

Figure 3.3: The properties of second condenser cut of bio-oil at different condensation temperatures.

\subsubsection{GC-MS analysis for aqueous and second condenser fractions}

The whole bio-oil from birch bark was phase separated at room temperature, and hence, GC-MS analysis could not be performed for the whole bio-oil. The initial phase separation of the whole bio-oil is likely due to the high content of extractives in birch bark. Oasmaa et al. reported a similar kind of initial phase separation with bio-oil from forestry residues with a high bark content [29]. This phase separation has found to be enhanced by increased temperature and longer storage time [8]. 


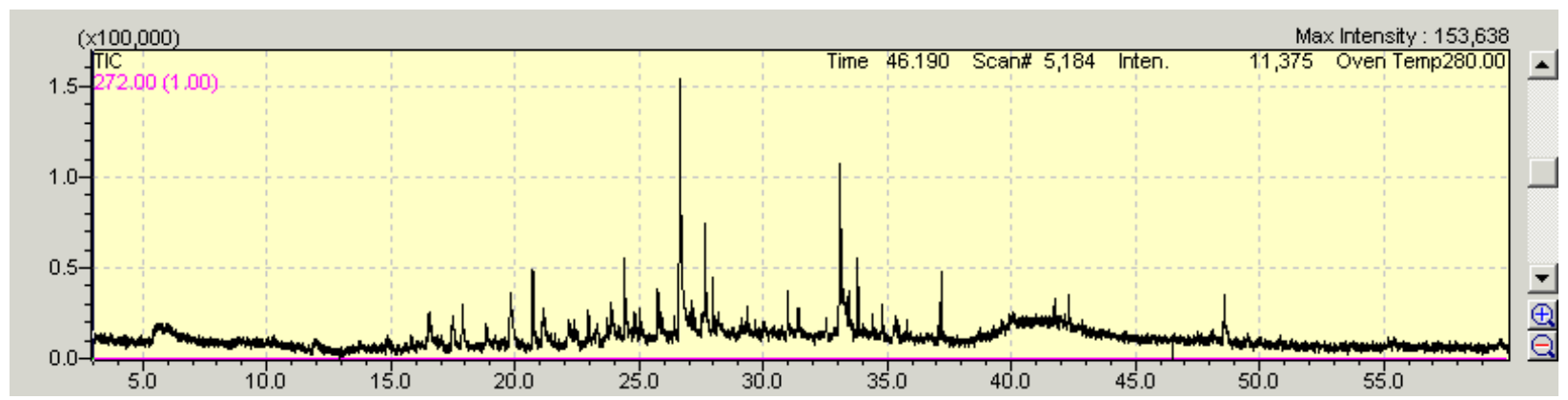

(a) Second condenser cut

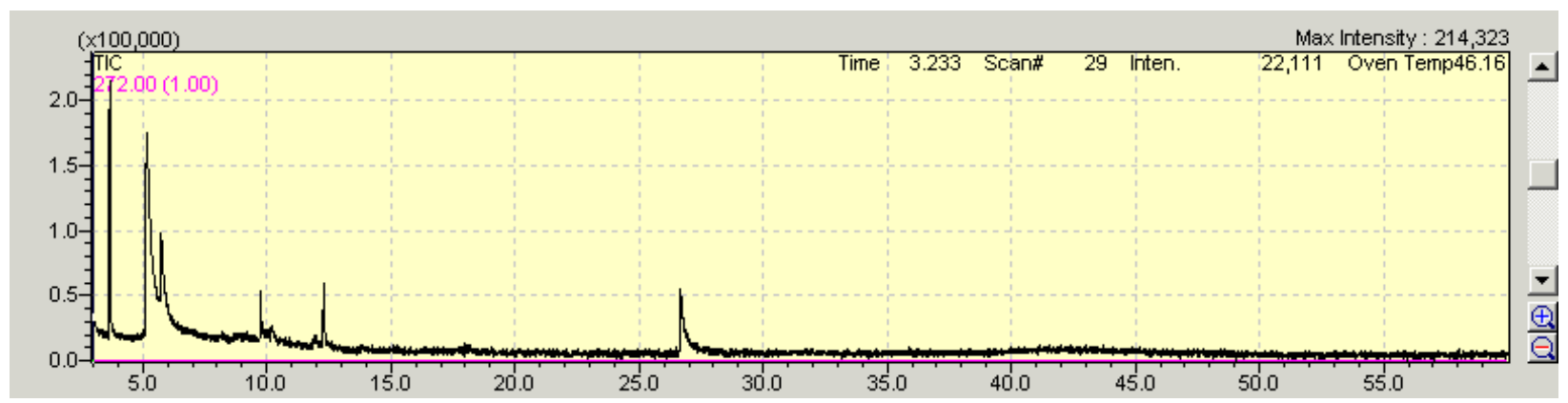

(b) Aqueous fraction

Figure 3.4: The GS-MS spectra for second condenser cut and aqueous cut.

Figure $3.4 \mathrm{~b}$ shows that the aqueous fraction mainly consists of water and light volatile organic components that were not present in the second condenser cut (Figure 3.4a). In a previous study, Oasmaa et al. stated that removal of light organic components such as aldehydes and ketones would enhance the stability of bio-oil [30]. Figure 3.4 shows that in the present study, the light organic components are concentrated in the aqueous fraction of the bio-oil, which means that the second condenser cut should be stable.

\subsubsection{Aging of different fractions of birch bark bio-oil}

\subsubsection{Second condenser cut}

Figure 3.5 shows the evolution of chemical compounds of the second condenser cut which was dissolved in $25 \mathrm{wt} \%$ isopropanol to make a liquid fuel and to reduce its viscosity. The viscosity of oil with $20 \%$ isopropanol was $182 \mathrm{cP}$ at $50{ }^{\circ} \mathrm{C}$ and viscosity was $110 \mathrm{cP}$ with $25 \%$ isopropanol at the same temperature. The concentration of all the reactive components such as 
acids, ketones, furans and aldehydes increased over the aging period. This might be due to the reaction of the heavy fractions of the bio-oil of the second condenser cut with isopropanol over the time, which would be very attractive.

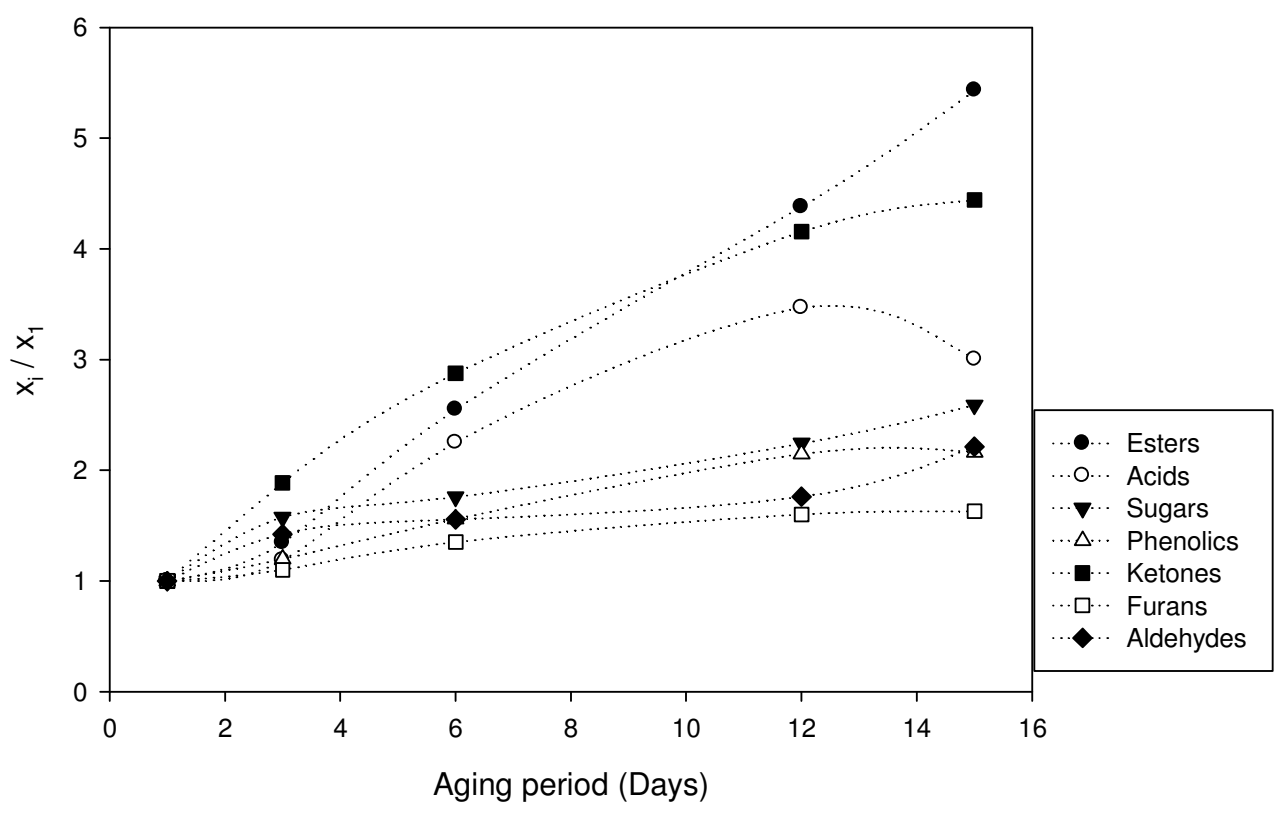

Figure 3.5: Change in chemical composition of second condenser cut over the aging period.

$$
\begin{aligned}
& \mathrm{x}_{1}=\frac{\text { Peak area of GC }- \text { FID for component } k \text { at time } 1}{\text { Peak area for internal standard at time } 1} \\
& \mathrm{x}_{i}=\frac{\text { Peak area of GC }- \text { FID for component } k \text { at time } i}{\text { Peak area for internal standard at time } i}
\end{aligned}
$$

The sugars and other carbohydrates originate mainly from the cellulose part of the original biomass, while phenols come from the lignin fraction and other reactive compounds such as acids, ketones and aldehydes result mainly from the pyrolysis of the hemicellulose fraction [31]. This explains the relatively low sugar concentration of the bio-oil, since the original birch bark has a relatively low cellulose content. 


\subsubsection{Mixture of second condenser cut and aqueous cut}

When the aqueous cut is added to the second condenser cut, the acid concentration decreased with time and the esters concentration increased. Since the aqueous fraction is rich in carboxylic acids, these acids reacted with isopropanol and produced esters during aging.

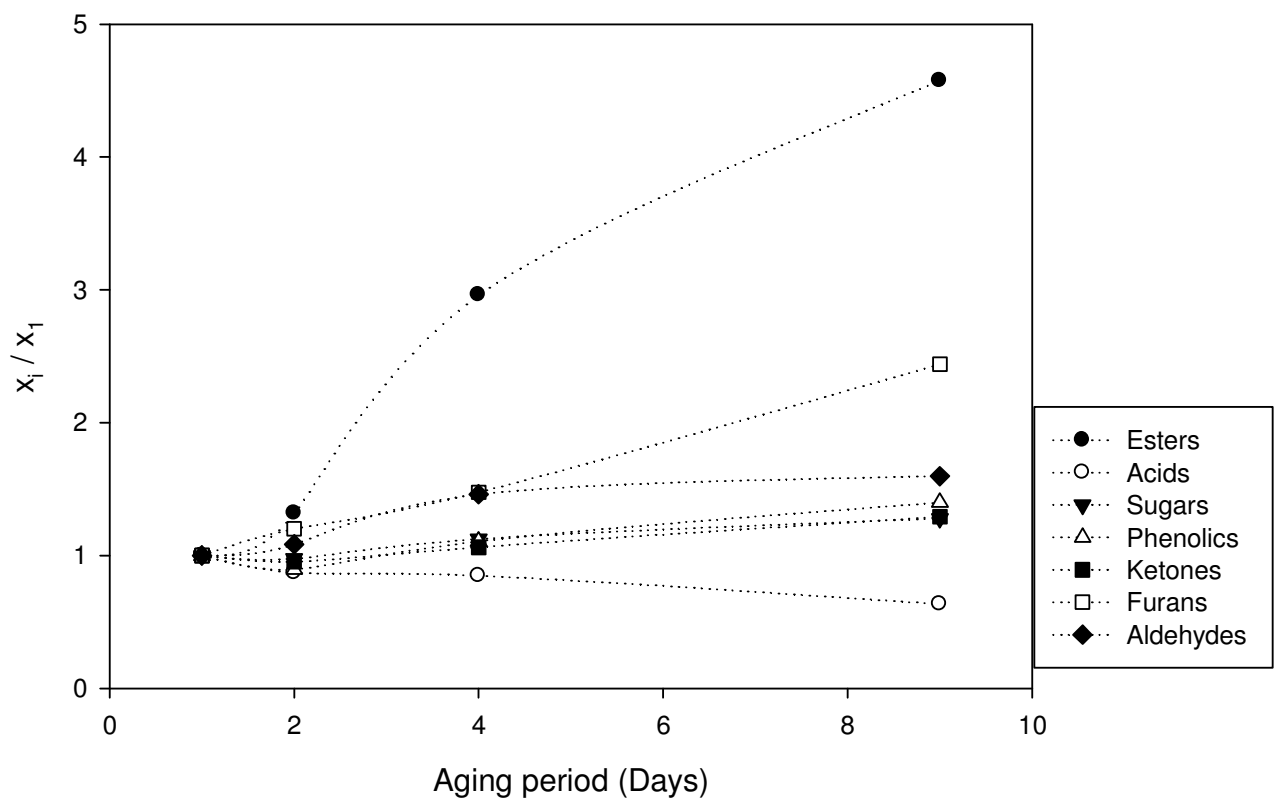

Figure 3.6: Change in chemical composition of the mixture of second condenser cut and aqueous cut (condenser 3 ) over the aging period.

$$
\begin{aligned}
& \mathrm{x}_{1}=\frac{\text { Peak area of GC }- \text { FID for component } k \text { at time } 1}{\text { Peak area for internal standard at time } 1} \\
& \mathrm{x}_{i}=\frac{\text { Peak area of GC }- \text { FID for component } k \text { at time } i}{\text { Peak area for internal standard at time } i}
\end{aligned}
$$

\subsubsection{Mixture of second condenser cut and solid cut}

When the solid cut is added to the second condenser cut, as shown in Figure 3.7, the concentrations of acid, ketones, aldehydes and furan peaked after about 3 days of aging at $80{ }^{\circ} \mathrm{C}$ and decreased for longer aging times. This is in sharp contrast with the aging of the second condenser cut, in which these concentrations increased steadily with the aging time (Figure 3.5). 
The concentration of esters increased at a lower rate compared to that in the second condenser cut.

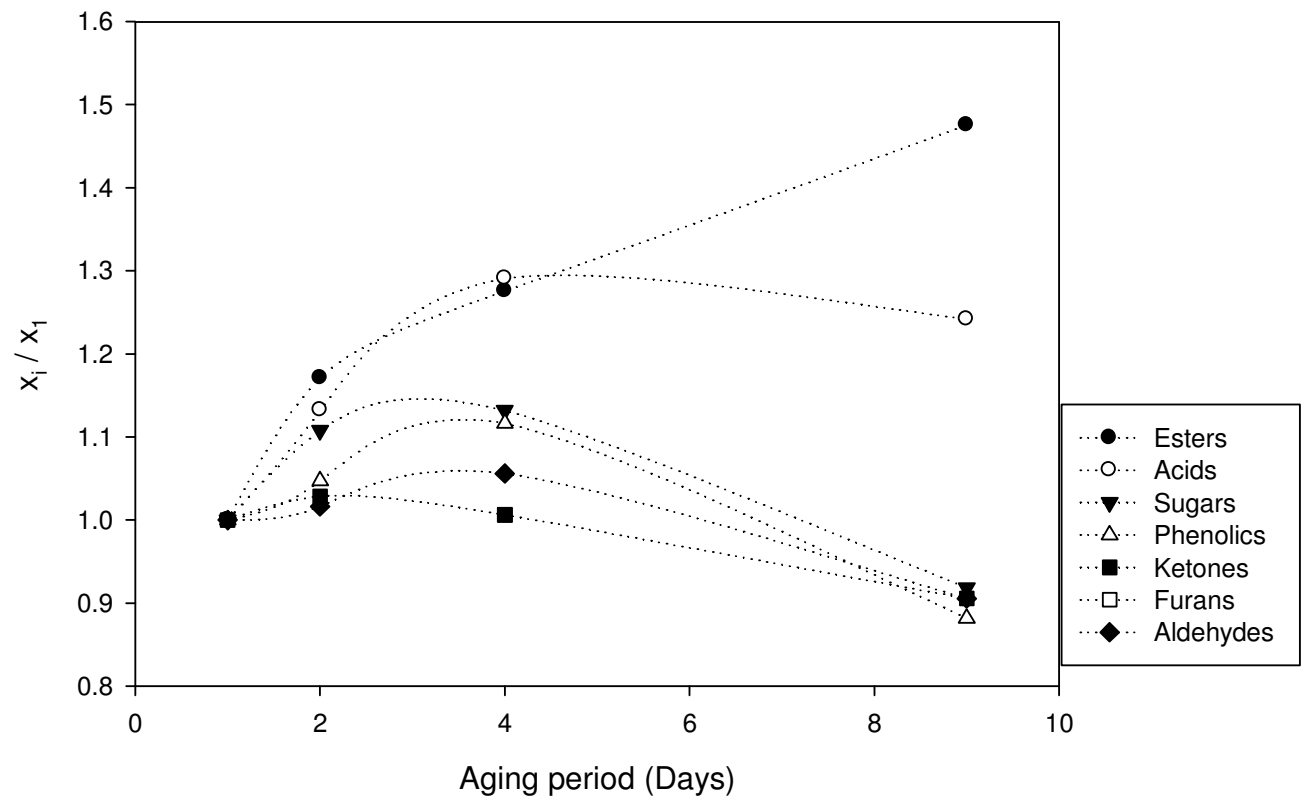

Figure 3.7: Change in chemical composition of combination of second condenser cut and solid cut (condenser 1) over the aging period.

$$
\begin{aligned}
& \mathrm{x}_{1}=\frac{\text { Peak area of GC }- \text { FID for component } k \text { at time } 1}{\text { Peak area for internal standard at time } 1} \\
& \mathrm{x}_{i}=\frac{\text { Peak area of GC }- \text { FID for component } k \text { at time } i}{\text { Peak area for internal standard at time } i}
\end{aligned}
$$

\subsubsection{Change in higher heating value of second condenser cut}

The change in HHV during the aging period is shown in Figure 3.8. Unlike during aging of normal bio-oil, the HHV of the second condenser cutdid not decreased during aging but, instead, increased slightly. Due to the initial phase separation, it has been impossible to measure the HHV of the whole bio-oil. 


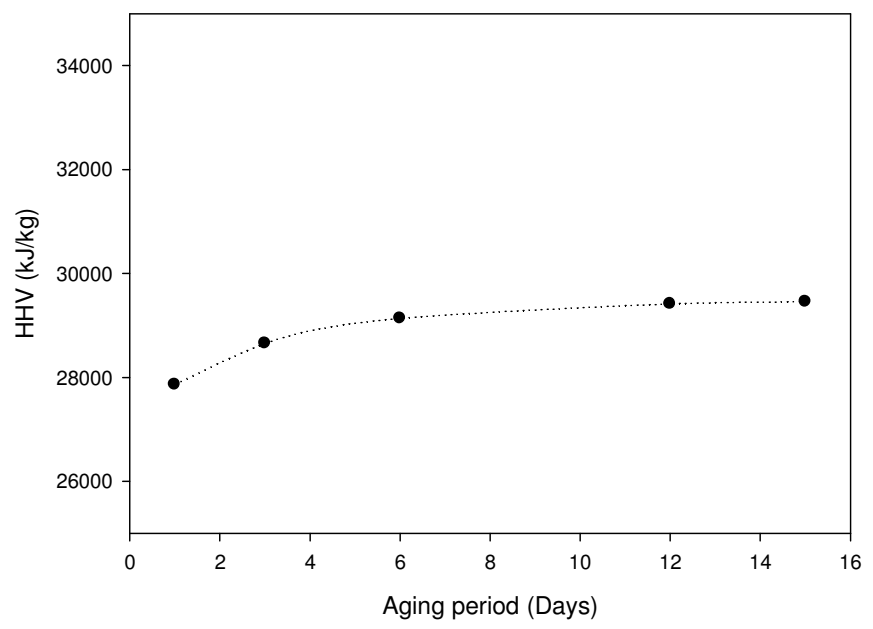

Figure 3.8: Change in higher heating value of second condenser cut over the aging period.

\subsection{Conclusions}

Whole bio-oil of birch bark, as produced, is not a single phase liquid at room temperature. Instead, due to the high content of extractives, it separates into two phases. Fractional condensation is an effective method to separate water, acids and other low molecular weight reactive components from the rest of the bio-oil.

The bio-oil vapors were separated into 3 cuts: a hard solid in the first condenser, a viscous oily cut ("second condenser cut") in the second condenser/electrostatic precipitator, and a water-rich acidic liquid in condenser 3 .

Adding isopropanol to the second condenser cut made it very stable. A concentration of about $25 \mathrm{wt} \%$ of isopropanol was required to reduce the viscosity so that it could be used as a liquid fuel. The viscosity of oil with $20 \%$ isopropanol was $182 \mathrm{cP}$ at $50{ }^{\circ} \mathrm{C}$ and viscosity was $110 \mathrm{cP}$ with $25 \%$ isopropanol at the same temperature.

In the second condenser cut mixed with isopropanol, the concentration of reactive compounds such as acids, ketones, furans and aldehydes, detectable by GC-MS, increases with aging. The heating value of this liquid also increases with aging. 
Performing fractional condensation and mixing the oil fractions with isopropanol yields a very stable liquid fuel.

\subsection{References}

[1] Diebold, J. P. (2000). A review of the chemical and physical mechanisms of the storage stability of fast pyrolysis bio-oils. NREL/SR-570-27613. Colorado, National Renewable Energy Laboratory.

[2] Diebold, J. P. and Czernik, S. (1997). Additives to lower and stabilize the viscosity of pyrolysis oil during storage. Energy \& Fuels 1997, 11, 1081-1091

[3] Oasmaa, A. and Kuoppala, E. (2003). Fast pyrolysis of forestry residue. 3. Storage stability of liquid fuel. Energy \& Fuels 2003, 17, 1075-1084

[4] Czernik, S., Johnson, D. K., Black, S. (1994). Stability of wood fast pyrolysis oil. Biomass and Bioenergy, 7(1-6), 187- 192.

[5] Oasmaa, A. and Czernik, S. (1999). Fuel oil quality of biomass pyrolysis oils- state of the art for the end users. Energy \& Fuels 1999, 13, 914-921.

[6] Demirbas, A. (2007). The influence of temperature on the yield of compounds existing in bio-oils obtained from biomass samples via pyrolysis. Fuel Processing Technology, 88(2007), 591-597.

[7] Batts, B.D. and Fathoni, A.Z. (1991). A literature review on fuel stability with particular emphasis on diesel oil. Energy \& Fuels 1991, 5, 2-21.

[8] Vispute, T. (2011). Pyrolysis oils: Characterization, stability analysis and catalytic upgrading to fuels and chemicals. Open access dissertation, paper 349, Amherst, University of Massachusetts. http://scholarworks.umass.edu/open_access_dissertations/349

[9] Oasmaa, A., Korhonen, J. and Kuoppala, E. (2011). An approach for stability measurement of wood-based fast pyrolysis bio-oil. Energy \& Fuels 2011, 25, 3307-3313. 
[10] Zhang, Q., Chang, J., Wang, T. and Xu, Y. (2006). Upgrading bio-oil over different solid catalysts. Energy \& Fuels 2006, 20, 2717-2720.

[11] Meng, J., Park, J., Tilotta, D., and Park, S. 2012. The effect of torrefaction on the chemistry of fast -pyrolysis bio-oil. Bioresource Technology, 111(2012), 439- 446

[12] Van der Stelt, M. J. C., Gerhauser, H., Kiel, J. H. A., and Ptasinski, K. J. 2011. Biomass upgrading by torrefacton for the production of biofuels: A review. Biomass and Bioenergy, 35(2011), 3748- 3762.

[13] Boateng, A. A., and Mullen, C. A. 2013. Fast pyrolysis of biomass thermally pretreated by torrefaction. Journal of Analytical and Applied Pyrolysis. 100(2013), 95- 102.

[14] Dong, C., Zhang, Z., Lu, Q., and Yang, Y. (2012). Characteristics and mechanism study of analytical fast pyrolysis of poplar wood. Energy conversion and Management, 57(2012), 49-59.

[15] Demirbas, A. (2007). The influence of temperature on the yields of compounds existing in bio-oils obtained from biomass samples via pyrolysis. Fuel Processing Technology, 88(2007), 591-597.

[16] Westerhof, R. J. M., Kuipers, N. J. M., Kersten, S. R. A., and van Swaaij, W. P. M. (2007). Controlling the Water Content of Biomass Fast Pyrolysis Oil. Industrial and Engineering Chemistry Research, 46 (2007).9238-9247.

[17] Garcia-Perez, M., Wang, S. X., Shen, J., Rhodes, M. J., Tian, F., Lee, W., Wu, H. C., and Li, C. (2008). Fast pyrolysis of Mallee woody biomass: Effect of temperature on the yield and quality of pyrolysis products. Industrial and Engineering Chemistry Research, 47 (2008), 1846-1854.

[18] Garcia-Perez, M., Wang, S., Shen, J., Rhodes, M., Lee, W. J., Li, C. Z. (2008). Effects of temperature on the formation of lignin-derived oligomers during the fast pyrolysis of Mallee woody biomass. Energy \& Fuels, 22 (3), 2022-2032. 
[19] Azeez, A. M., Meier, D., Odermatt, J. and Willner, T. (2010). Fast pyrolysis of African and European lignocellulosic biomasses using Py-GC/MS and fluidized bed reactor. Energy \& Fuels 2010, 24, 2078-2085.

[20] Guo, Z. G., Wang, S. R., Zhu, Y. Y., Luo, Z. Y. and Cen, K. F. (2009). Separation of acid compounds for refining biomass pyrolysis oil. Journal of Fuel Chemistry and Technology 2009, 37(1), 49-52.

[21] Oasmaa, A., Sipila, K., Solantausta, Y. and Kuoppala, E. (2005). Quality improvement of pyrolysis liquid: Effect of light volatiles on the stability of pyrolysis liquids. Energy \& Fuels 2005, 19, 2556-2561.

[22] Westerhof, R. J. M., Brilman, D. W. F., Garcia-Perez, M., Wang, Z., Oudenhoven, S. R. G., van Swaaij, W. P. M. and Kersten, S. R. A. (2011). Fractional condensation of biomass pyrolysis vapours. Energy \& Fuels 2011, 25, 1817-1829.

[23] Pollard, A. S., Rover, M. R., and Brown, R. C. (2012). Characterization of bio-oil recovered as stage fractions with unique chemical and physical properties. Journal of Analytical and Applied Pyrolysis. 93(2012), 129-138.

[24] Tzanetakis, T., Ashgriz, N., james, D. F., and Thomson, M. J. (2008). Liquid fuel properties of a hardwood derived bio-oil fraction. Energy \& Fuels, 22(2008), 2725-2733.

[25] Tumbalam Gooty, A. 2012. Fractional condensation of bio-oil vapors. University of Western Ontario - Electronic Thesis and Dissertation Repository. Paper 979. http://ir.lib.uwo.ca/etd/979

[26] Chang, C. C., Wu, S. R., Lin, C. C., Wan, H. P. and Lee, H. T. (2012). Fast pyrolysis of biomass in pyrolysis gas: fractionation of pyrolysis vapors using a spray of bio-oil. Energy \& Fuels 2012, 26, 2962-2967.

[27] Chen, T., Deng, C., and Liu, R. (2010). Effect of selective condensation on the characterization of bio-oil from pine sawdust fast pyrolysis using a fluidized bed reactor. Energy \& Fuels, 24(2010), 6616-6623. 
[28] Guo, X., Wang, S., Guo, Z., Liu, Q., Luo, Z and Cen K. (2010). Pyrolysis characteristics of bio-oil fractions separated by molecular distillation. Applied Energy, 87(2010), 28922898.

[29] Oasmaa, A., Kuoppala, E., Gust, S., and Solantausta, Y. (2003). Fast pyrolysis of forestry residue. 1. Effect of extractives of phase separation of pyrolysis liquids. Energy \& Fuels, $17(1), 1-12$.

[30] Oasmaa, A.,Sipila, K., Solantausta, Y., and Kuoppala, E. (2005). Quality improvement of pyrolysis liquid: Effect of light volatiles on the stability of pyrolysis liquid. Energy \& Fuels, 19(2005), 2556-2561.

[31] Qu, T., Guo, W., Shen, L., Xiao, J. and Zhao, K. (2011). Experimental study of biomass pyrolysis based on three major components: Hemicellulose, cellulose and lignin. Industrial \& Engineering Chemistry Research 2011, 50, 10424-10433. 


\section{Chapter 4}

\section{Conclusions and recommendations}

\subsection{Conclusions}

It was observed that, as it is, phase separation of bio-oil is not an effective tool to segregate one or more component into a single phase. Under accelerated aging conditions at $80{ }^{\circ} \mathrm{C}$, hardwood derived bio-oil (BTG oil) was phase separated after 15 hours of aging. During prolonged aging, the proportion of the viscous bottom phase will continue to gradually increase. GC-MS analysis shows that, during accelerated aging, some phenolic, sugar, ketone, ester, acid, furan and aldehyde components are disappearing from the fraction of the bio-oil that is light enough for GC detection. These components might undergo polymerization or condensation reactions with the heavy pyrolytic fraction of bio-oil.

The addition of solvents greatly retards phase separation. Amongst the various alcohols that were studied (isopropanol, ethanol, propanol and butanol), isopropanol is most effective at retarding phase separation. The addition of a polar solvent such as isopropanol not only increases the mutual solubility of the bio-oil components, but also changes the chemical composition through reactions such as esterification.

The model compounds study shows that carboxylic acids are converted to esters in the presence of alcohol and these esters seem to be very stable at elevated temperatures for prolonged periods of time. On the other hand, most of the derivatives from linear ketones and aldehydes (mainly acetals) are not stable at experimental conditions. They either decompose into other products or

react to form higher molecular weight components that are undetectable by GC-MS. The same results were observed with furan and furan derivatives. Furan and aldehydes react and disappear very quickly. On the other hand, phenolic compounds such phenol, vanillin and guaiacol are stable.

Whole bio-oil from the fast pyrolysis of birch bark is phase separated at room temperature, probably because of the high extractives content of the bark. Fractional condensation is an effective method to separate water, acids and other low molecular weight reactive components from bio-oil. In the oil rich second condenser cut, the concentration of reactive compounds such 
as acids, ketones, furans and aldehydes that is detected by GC-MS, increases with aging. At the presence of aqueous fraction or the solid fraction, the increase in reactive component groups are not very significant compared to the fraction from condenser 2. The HHV value of second condenser cut does not decrease with aging time. However, since the addition of $25 \%$ isopropanol was required to make it a liquid fuel and to reduce its viscosity, the stability might come from the removal of light volatile components in fractionation, from the addition of alcohol or the combination of the two.

\subsection{Recommendations}

- Since the study of phase separation in Chapter 1 is performed under accelerated aging conditions, the main results should be verified under aging at room temperature.

- The aging and phase behaviour of bio-oil of different feedstocks at different percentages of alcohols would be of use.

- The results in Chapter 2 shows that most of the furans, aldehydes and their derivatives are not detected with GC-MS even just after mixing. Therefore, it can be concluded that these high volatile chemicals have reacted or decomposed into other components. The question is whether these reactions occurred during aging or in the high temperature oven of the GCMS. The high temperature of the GC-MS oven might also be affecting other reactions that were attributed to aging. Some of the most important results obtained with the GC-MS should, therefore be checked with HPLC where the column temperature is much lower.

- It would also be useful to run the model compound study with different combinations of model compounds; such as no acid case, no furan case, no aldehyde case etc. That way, it would be easy to identify which component is making the mixture more stable or unstable. 
Appendix A: Example of manual integration of GC-MS/FID data for the points of time $=3 \mathrm{hrs}$ of aging in Figure 1.2.

\begin{tabular}{|c|c|c|c|c|c|c|c|c|}
\hline \multirow[b]{2}{*}{$\begin{array}{l}\text { Component } \\
\text { group }\end{array}$} & \multirow[b]{2}{*}{ Chemical component } & \multicolumn{3}{|c|}{ At time $=1 \mathrm{hrs}$} & \multicolumn{3}{|c|}{ At time $=3 \mathrm{hrs}$} & \multirow[b]{2}{*}{$\mathrm{x}_{3} / \mathrm{x}_{1}$} \\
\hline & & $\begin{array}{l}\text { Peak } \\
\text { area }\end{array}$ & $\begin{array}{l}\text { Sum of } \\
\text { peaks }\end{array}$ & $\begin{array}{l}\text { Sum of } \\
\text { peaks/peak } \\
\text { of internal } \\
\text { standard } \\
\left(x_{1}\right) \\
\end{array}$ & $\begin{array}{l}\text { Peak } \\
\text { area }\end{array}$ & $\begin{array}{l}\text { Sum of } \\
\text { peaks }\end{array}$ & $\begin{array}{l}\text { Sum of } \\
\text { peaks/peak } \\
\text { of internal } \\
\text { standard } \\
\left(\mathrm{x}_{3}\right) \\
\end{array}$ & \\
\hline $\begin{array}{l}\text { Internal } \\
\text { Standard }\end{array}$ & 1-Dodecanol & 98009 & & & 92831 & & & \\
\hline \multirow[t]{2}{*}{ Acids } & Acetic acid & 52670 & & & 52035 & \multirow[b]{2}{*}{53538} & \multirow[b]{2}{*}{0.57672308} & \multirow[b]{2}{*}{1.0461} \\
\hline & $\begin{array}{l}\text { 2-Naphthalenecarboxylic acid, 4,4'-methylenebis[3- } \\
\text { methoxy- }\end{array}$ & 1362 & 54032 & 0.55129712 & 1502 & & & \\
\hline \multirow[t]{11}{*}{ Ketones } & 2-Propanone, 1-hydroxy-, oxime & 10483 & & & & \multirow[b]{11}{*}{111831} & \multirow[b]{11}{*}{1.20466456} & \multirow[b]{11}{*}{0.9694} \\
\hline & 2-Propanone, 1-hydroxy- & 59250 & & & 57668 & & & \\
\hline & 2-Cyclopenten-1-one, 3-methyl- & 5291 & & & 6345 & & & \\
\hline & 2-Cyclopenten-1-one, 2,3-dimethyl- & 1775 & & & 1762 & & & \\
\hline & 1,2-Cyclopentanedione, 3-methyl- & 24758 & & & 24531 & & & \\
\hline & 3',5'-Dihydroxyacetophenone & 1995 & & & 1858 & & & \\
\hline & Ethanone, 1-(4-hydroxy-3-methoxyphenyl)- & 7922 & & & 8050 & & & \\
\hline & 2-Propanone, 1-(4-hydroxy-3-methoxyphenyl)- & 4773 & & & 4911 & & & \\
\hline & Ethanone, 1-(4-hydroxy-3-methoxyphenyl)- & 1102 & & & 1135 & & & \\
\hline & 2-Butanone, 4-(4-hydroxy-3-methoxyphenyl)- & 1739 & & & 1501 & & & \\
\hline & $\begin{array}{l}\text { 2-Cyclohexen-1-one, 3-(3-hydroxybutyl)-2,4,4- } \\
\text { trimethyl- }\end{array}$ & 2707 & 121797 & 1.2427103 & 4066 & & & \\
\hline \multirow[t]{3}{*}{ Sugars } & 2,3-Anhydro-d-galactosan & 3174 & \multirow[b]{3}{*}{138052} & \multirow[b]{3}{*}{1.4085618} & 4006 & \multirow[b]{3}{*}{138311} & \multirow[b]{3}{*}{1.4899102} & \multirow[b]{3}{*}{1.0578} \\
\hline & 2,3-Anhydro-d-mannosan & 4079 & & & 3074 & & & \\
\hline & 1,4:3,6-Dianhydro-.alpha.-d-glucopyranose & 3476 & & & 3404 & & & \\
\hline
\end{tabular}




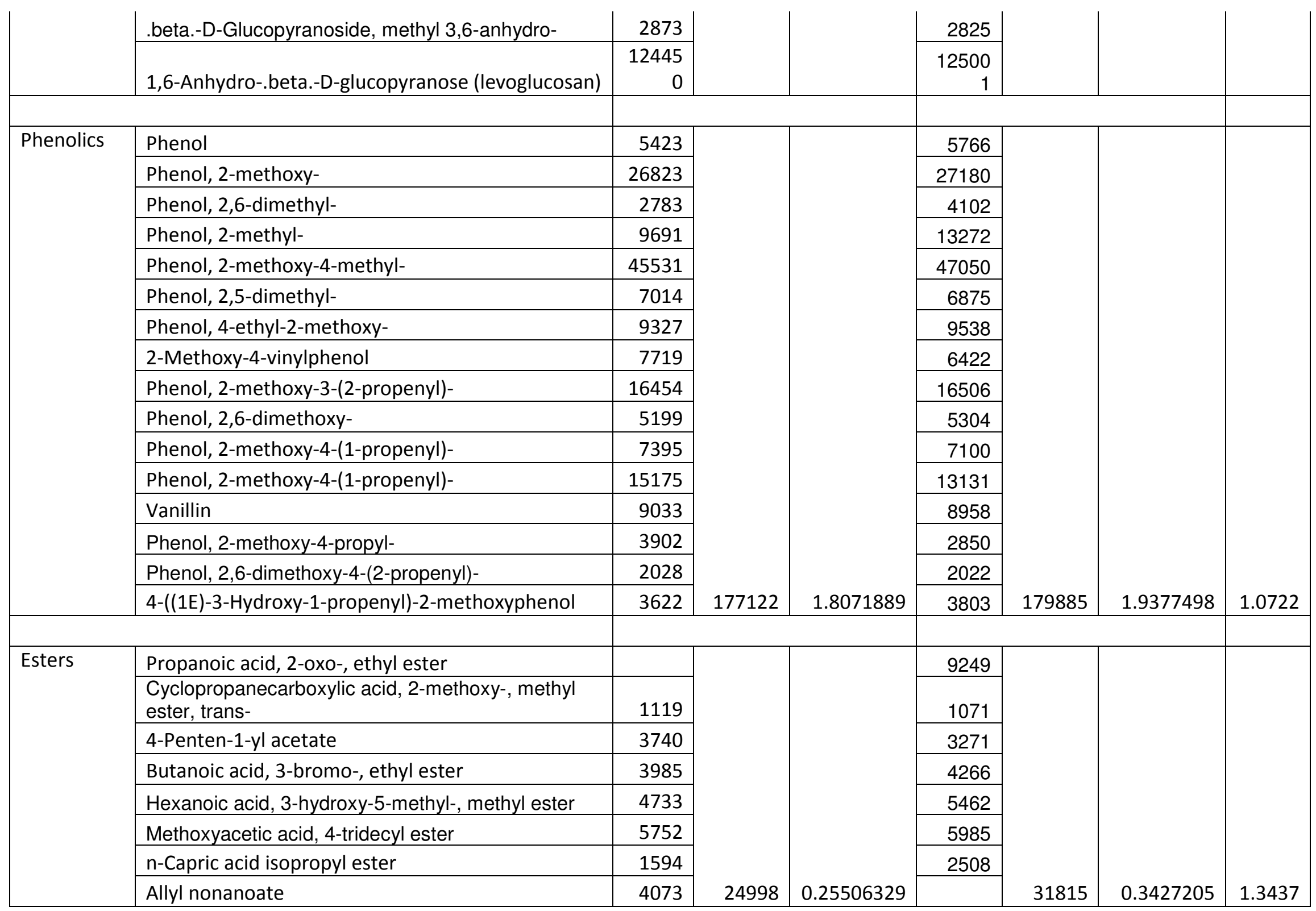




\begin{tabular}{|c|c|c|c|c|c|c|c|c|}
\hline \multirow[t]{6}{*}{ Furans } & Furan, tetrahydro-2,5-dimethoxy- & 12758 & \multirow[b]{6}{*}{45969} & \multirow[b]{6}{*}{0.4690346} & 14120 & \multirow[b]{6}{*}{49239} & \multirow[b]{6}{*}{0.5304168} & \multirow[b]{6}{*}{1.1309} \\
\hline & Furan, 2-(2-ethoxy-1-methoxyethyl)- & 13510 & & & 14084 & & & \\
\hline & Furan, tetrahydro-2,5-dimethoxy- & 6154 & & & 6370 & & & \\
\hline & $2(5 \mathrm{H})$-Furanone & 6840 & & & 7378 & & & \\
\hline & 2-Furanol, tetrahydro-2,3-dimethyl-, trans- & 2547 & & & 3104 & & & \\
\hline & $\begin{array}{l}\text { 2,5-Methano-2H-thiopyrano[3,2-b]furan, } \\
\text { hexahydro- }\end{array}$ & 4158 & & & 4182 & & & \\
\hline \multirow[t]{3}{*}{ Aldehydes } & Benzaldehyde, 4-hydroxy-3,5-dimethoxy- & 1310 & \multirow[b]{3}{*}{21183} & \multirow[b]{3}{*}{0.21613335} & 1142 & \multirow[b]{3}{*}{21084} & \multirow[b]{3}{*}{0.22712020} & \multirow[b]{3}{*}{1.0508} \\
\hline & 4-Hydroxy-2-methoxycinnamaldehyde & 15669 & & & 15845 & & & \\
\hline & 3,5-Dimethoxy-4-hydroxycinnamaldehyde & 4204 & & & 4096 & & & \\
\hline
\end{tabular}




\section{Appendix B: Curriculum Vitae}

\section{Education}

- Master of Engineering (MEng) in Energy Technology at the Asian Institute of Technology (AIT), Thailand. 96\%

- Bachelor of the Science in Engineering (BSc Eng) in Chemical and Process Engineering at University of Peradeniya, Sri Lanka. Honors Pass 2003

\section{Publications}

Thesis

- Development of a sustainable energy management standard for the industry sector in Sri Lanka (2009). Masters Thesis No. ET-09-04, Asian Institute of Technology, Thailand.

Journal papers

- Siriwardhana, M. 2009. Bio-diesel: initiatives, potential and prospects in Thailand: A review. Energy Policy. 37, 554-559.

- Siriwardhana, M. et al. 2009. Sri Lankan Rainfall Climate and its Modulation by El Nino and La Nina Episodes. Engineer. XXXXII (2), pp11-24, The Institute of Engineers Sri Lanka.

- Siriwardhana, M. et al. 2008. Predictability of Sri Lanka rainfall based on ENSO. Intrl. Journal of Climatology. 28:1, 91-101.

Research Reports

- Review of the status of biomass gasification in Thailand and Cambodia, submitted to the EEP Mekong Region.

- Energy Security Policy Brief and synthesis report in the context of developing countries, 2010, prepared for GNESD based on a research from 8 developing countries in Asia, Africa and Latin America. Available at GNESD website.

- Bioenergy; potential and status in Thailand and Indonesia, 2010, prepared for GNESD bioenergy theme project.

\section{Training and volunteering}

- Trainer in green productivity and energy efficiency, Asian Productivity Organization, Japan, 2008

- Reviewer of Energy, and Energy Policy, two international journals of Elsevier, since 2010. 